\title{
Dynamiques identitaires anciennes et actuelles chez les Aché du Paraguay oriental : éléments de compréhension
}

Philippe Edeb Piragi

\section{(2) OpenEdition}

\section{Journals}

Édition électronique

URL : https://journals.openedition.org/jsa/11961

DOI : 10.4000/jsa.11961

ISSN : 1957-7842

Éditeur

Société des américanistes

Édition imprimée

Date de publication : 20 décembre 2011

Pagination : 231-285

ISSN : 0037-9174

Référence électronique

Philippe Edeb Piragi, « Dynamiques identitaires anciennes et actuelles chez les Aché du Paraguay oriental : éléments de compréhension », Journal de la Société des américanistes [En ligne], 97-2 | 2011, mis en ligne le 10 décembre 2014, consulté le 04 septembre 2022. URL : http:// journals.openedition.org/jsa/11961 ; DOI : https://doi.org/10.4000/jsa.11961 


\title{
DYNAMIQUES IDENTITAIRES ANCIENNES ET ACTUELLES \\ CHEZ LES ACHÉ DU PARAGUAY ORIENTAL : ÉLÉMENTS DE COMPRÉHENSION
}

\author{
Philippe EDEB PIRAGI *
}

\begin{abstract}
À partir d'une ethnographie débutée en 1986, l'auteur analyse les moteurs de l'affirmation identitaire, explorant les représentations du soi et de l'autre chez les Aché du Paraguay oriental, qui ont su résister notablement, au long de leur histoire, à l'assimilation par les Guarani. Après la fixation forcée dans des réserves sous tutelle missionnaire, parachevée en 1978, les découpages géopolitiques ont été remplacés par une nouvelle compartimentation de cette société nomade en colonies permanentes et indépendantes. La perte des territoires ancestraux a désarticulé l'unité sociopolitique ache gatu, consubstantielle à l'identité ethnique des groupes du Sud et du Nord. Le retour des captifs élevés parmi les Blancs a, lui aussi, transformé les contours sociologiques de la colonie sédentaire et compliqué la connaissance des Aché et des enjeux contemporains. Néanmoins, le processus de résurgence ethnique et de revendication territoriale, observable à partir de 2000, révèle que les quatre derniers sous-groupes aché gatu, ont su dépasser leurs différences linguistiques et culturelles traditionnelles - sans pour autant y renoncer -, pour se fédérer en 2008 et s'affirmer comme un peuple en soi et pour soi. [Mots-clés : Paraguay, chasseurs-cueilleurs, sédentarisation, identité ethnique, territoire, langue.]
\end{abstract}

Dinámicas identitarias antiguas y actuales entre los aché del Paraguay Oriental : elementos de comprensión. Sobre la base principal de una etnografía iniciada en 1986, el autor analiza los mecanismos de la afirmación identitaria, explorando las representaciones de sí y del otro entre los aché del Paraguay Oriental, que supieron resistir notablemente, a lo largo de su historia, a la asimilación por los guaraníes. Después de la fijación forzosa en asentamientos bajo tutela misionera, completada en 1978, las divisiones geopolíticas han sido sustituidas por una nueva compartimentación de esta etnia nómada en colonias permanentes e independientes. La pérdida de los territorios ancestrales desarticuló la unidad sociopolítica ache gatu, consustancial a la identidad étnica de los grupos sureños y norteños. El retorno de los cautivos criados entre los blancos ha transformado, también, los contornos sociológicos de la colonia sedentaria, complicando el conocimiento de los aché y de sus desafíos contemporáneos. Sin

* Anthropologue, conseiller, LINAJE, Pa’i Pérez 759, Asunción, Paraguay [linaje79@gmail.com]. Journal de la Société des Américanistes, 2011, 97-2, pp. 231-285. C Société des Américanistes. 
embargo, el proceso de resurgimiento étnico y reivindicación territorial, observable a partir del 2000, revela que los cuatro últimos subgrupos aché gatu supieron superar sus diferencias lingüísticas y culturales tradicionales - sin renunciar a éstas - para federarse en 2008 y afirmarse como un Pueblo en sí y por sí. [Palabras claves: Paraguay, cazadores-recolectores, sedentarismo, identidad étnica, territorio, lengua.]

Keys to understanding ancient and current identity dynamics among the Ache of Eastern Paraguay. Based on fieldwork begun in 1986, the author analyses the driving forces behind Aché self-assertion, exploring the conceptions of self and other of this Eastern Paraguayan group of tupi speakers who have repeatedly and successfully resisted assimilation by the Guarani. Following forced settlement in Mission-run reservations which was completed in 1978, older geopolitical segmentations were replaced by a new distribution of this nomadic society in permanent and independent colonies. Loss of ancestral territory dismembered the former socio-political unit, ache gatu, which was a crucial component of ethnic identity for the Southern and Northern groups. The return of people raised as captives among the Whites also had a great sociological impact, adding complexity to Aché knowledge and the challenges that awaited them. However, resurgence of ethnic and territorial claims, apparent since 2000 , led to the federation, in 2008, of the four last remaining ache gatu sub-groups, who managed to retain yet supersede their traditional linguistic and cultural differences to assert themselves as one People, in itself and for itself. [Key words : Paraguay, hunters-gatherers, sedentary settlement, ethnic identity, territory, language.]

Les Aché (Guayaki) du Paraguay oriental, groupe de chasseurs-cueilleurs appartenant à la famille tupi-guarani, sont d'anciens nomades de la forêt subtropicale dont les dernières bandes libres furent sédentarisées durant les années 1970. Ils ne constituaient plus alors que quatre sous-groupes (Figure 1), rattachés chacun à un territoire spécifique et parlant un dialecte propre. Ils se considéraient mutuellement comme des "non-compagnons » (irô-iâ), en d'autres termes comme des ennemis potentiels ou avérés. Ces sous-groupes qui s'auto-dénomment Aché gatu ${ }^{1}$ ("gens de référence », " gens authentiques ») cohabitent à présent. Ils se regroupent en sept colonies distribuées au sein de quatre départements de la région orientale (Caazapá, Alto Paraná, Caaguazú, Canindeyú), comptant aujourd'hui près de 400 familles et 1650 personnes (Figure 2) :

- dans le département de Canindeyú, les Aché septentrionaux, majoritaires, sont répartis dans quatre communautés: Chupa Pou (120 familles, 520 personnes), Arroyo Bandera (35 familles), Kuetuvy (55 familles) et Kuêtuwyve (7 familles);

- dans le département de Caaguazú, la colonie de Cerro Moroti (35 familles) créée en 1968, reste le fief principal des Aché de l'Yvytyrusu (ou Aché purâ) malgré l'essaimage de ses familles dans les autres communautés entre 2000 et 2010, et bien que les Aché du Nord soient dominants numériquement ; 


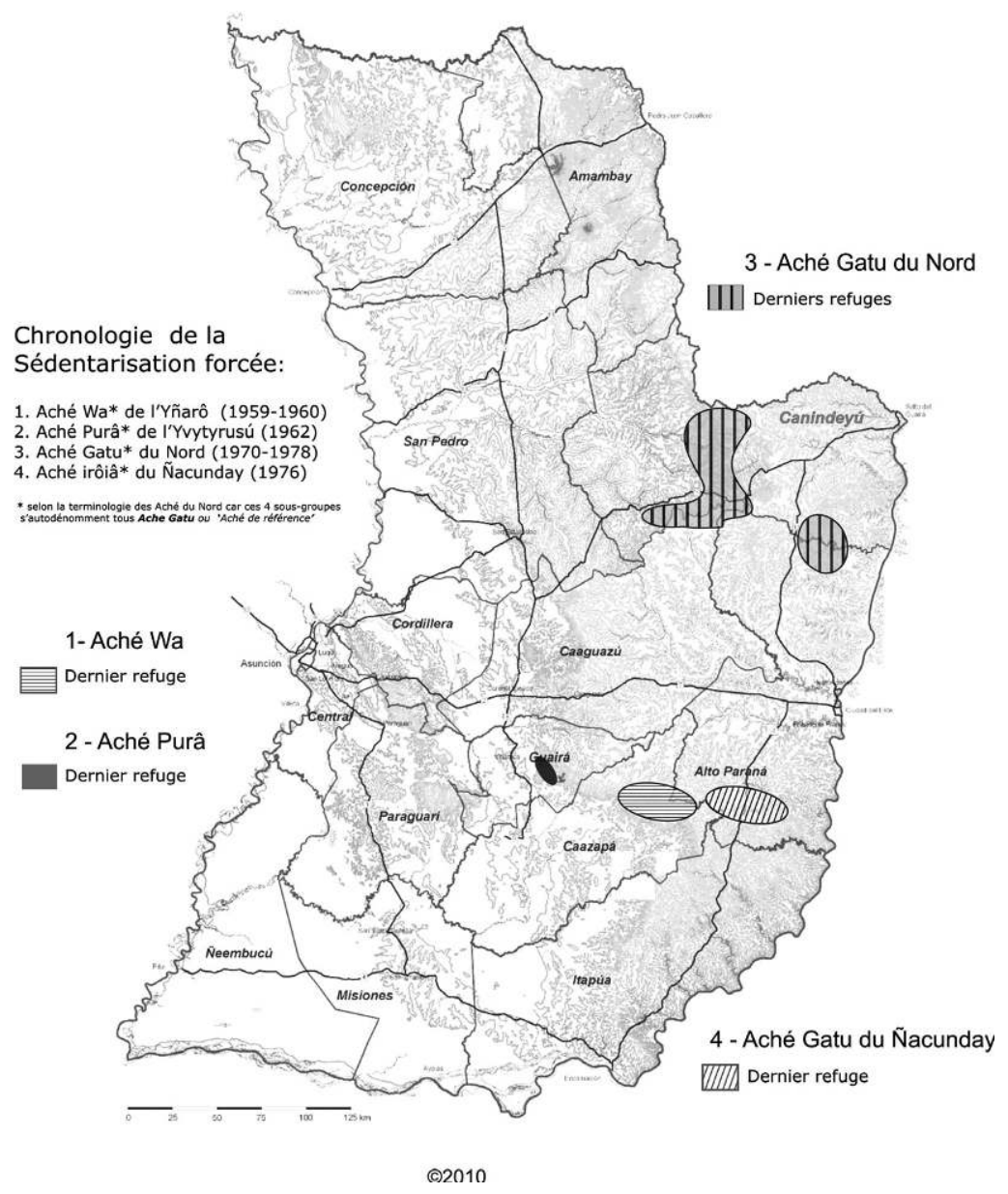

FIG. 1 - Derniers réduits nomades (carte de l'auteur).

- dans le département de Caazapá, les Aché wa vivent au sein de la communauté de Ypetimí ( \pm 90 familles, 400 personnes), où ils représentent un peu moins de $35 \%$ environ de la population ; là aussi, la très large majorité des habitants sont des Aché du Nord ( $\pm 50 \%$ ), le reste $(15 \%)$ étant constitué principalement de familles ou de membres aché purâ ;

- dans le département de l'Alto Paraná, les Aché du río Nacunday se concentrent presque exclusivement à Puerto Barra (40 familles). 


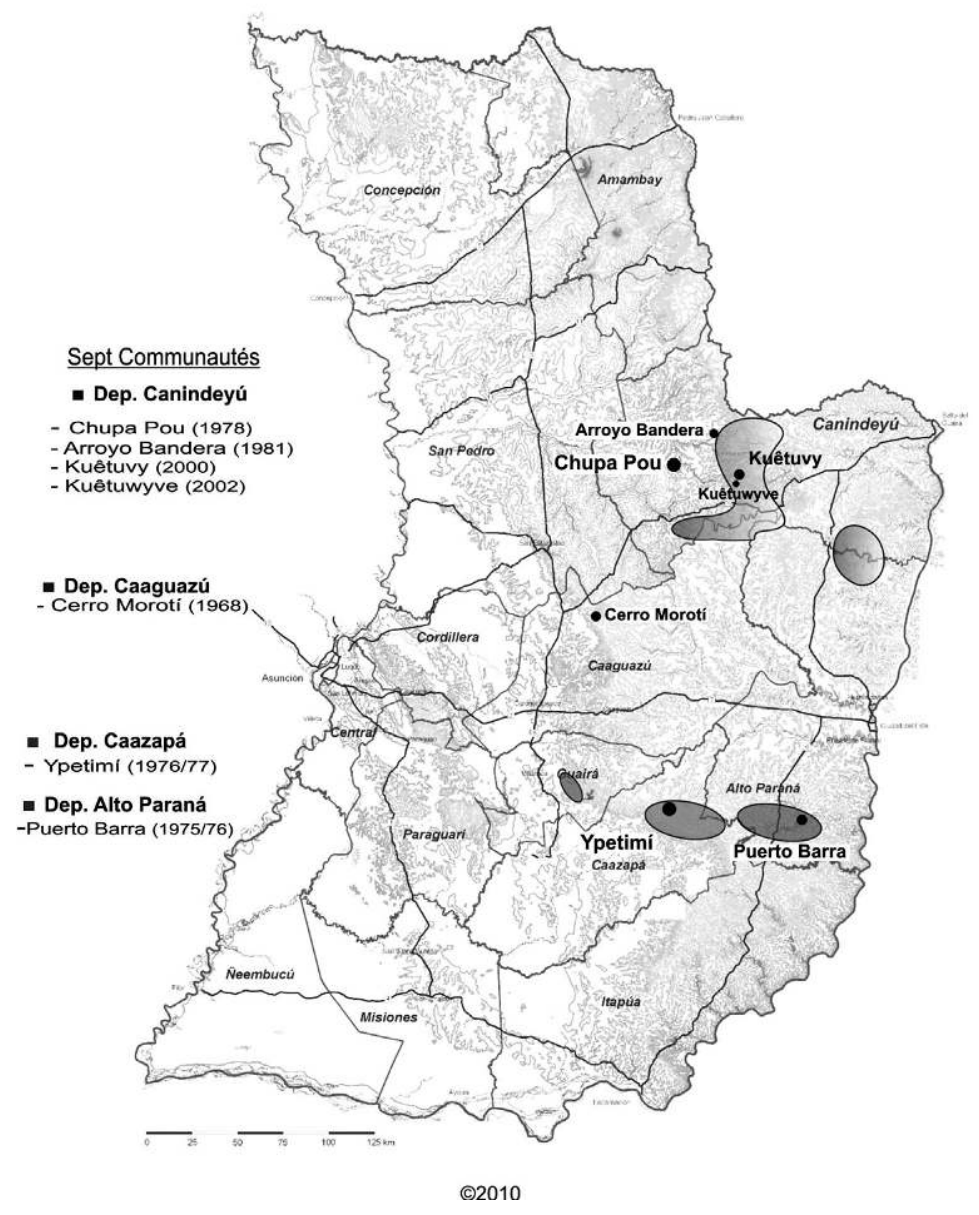

FIG. 2 - Communautés aché sédentaires actuelles (carte de l'auteur).

Aujourd'hui, les séparations géopolitiques entre les sous-groupes aché gatu n'ont donc plus cours, mais les différences linguistiques (intonation, vocabulaire, idiotismes...) et les particularismes culturels continuent à véhiculer, bien qu'atténués, quelques ostracismes traditionnels, à maintenir des distinctions sociologiques, certes souvent imperceptibles pour un observateur extérieur, mais bien réelles.

Il ne faudrait pas sous-estimer, néanmoins, la capacité d'unification du groupe qui a su opérer un réveil salutaire, à partir de 2000, en s'organisant politiquement et en se fédérant, ni ignorer la surprenante résilience de cette société nomade face 
aux profondes mutations socio-économiques et religieuses qui la secouent depuis la sédentarisation forcée des années 1960 et 1970 (Edeb Piragi 2005 ; 2008).

Les défis qu'il doit continuer à affronter et à vaincre ne sont pas minimes : le recul catastrophique de la forêt subtropicale, l'essor démographique incontrôlé, le manque de terres et de perspectives économiques claires, la labilité de ses contours identitaires contemporains...

\section{UN ÉTAT DES LIEUX DE L'ETHNOGRAPHIE}

\section{La pacification forcée}

Peuplant les sylves les plus impénétrables du Paraguay oriental, les Aché furent confrontés à la présence des Blancs depuis le XVII ${ }^{\mathrm{e}}$ siècle ${ }^{2}$ au moins, mais ne consentent à entrer en contact physique avec l'Occident qu'au tout début du $\mathrm{XX}^{\mathrm{e}}$ siècle : en 1910, une vingtaine d'Aché peuplant les forêts méridionales de Encarnación et Trinidad (actuel département de Itapua), acceptent de nouer les premières relations pacifiques connues et documentées à ce jour avec Friedrich C. Mayntzhusen, un émigrant allemand passionné de sciences, qui tentait de les contacter depuis 1903. Apprenant leur langue et passant plusieurs semaines consécutives avec eux en forêt, il étudie leur culture et amasse les premières données ethnographiques fiables (Mayntzhusen 1911, 1912, 1919-1920, 1925, 2009 ; Baldus 1972). Gagnant la confiance de ce groupe méridional, il convainc plusieurs de ses bandes de venir travailler sur ses terres et crée la toute première colonie d'Indiens guayaki. Après la mort de son fondateur en 1949, celle-ci sera dissoute et sa population dispersée sans que l'on ne sache jamais ce qu'elle est devenue.

Il faudra ensuite attendre les années 1960 pour que l'ethnolinguiste, Branislava Susnik, et l'éminent spécialiste des Guarani, León Cadogan, entreprennent d'étudier les derniers survivants des Aché wa : vaincu par la disparition des forêts de Caazapá, ce groupe résiduel de 30 personnes est venu se placer, à partir d'août 1959, "sous la protection » de Manuel Jesus Pereira, un ancien fonctionnaire de l'armée, faux protecteur des Indiens, plutôt en quête de subsides gouvernementaux et d'esclaves...

Grâce à ces Aché du Sud qui se révèlent des pisteurs zélés, Pereira peut entreprendre de traquer les Aché de l'Yvytyrusu, petite troupe de 60 personnes située un peu plus à l'est, qu'il déplace en 1962 sur ses terres à Arroyo Morotí (Cadogan et Colleville 1963, 1964 ; Clastres 1967, 1972 ; Clastres et Sebag 1964); puis il se lance, à partir de 1970, dans le contact forcé et la sédentarisation des Aché du Nord en isolement volontaire, mieux préservés et forts de 600 à 700 individus approximativement. Leur territoire situé au nord-est de la région orientale, en plein cœur des zones de drainage du río Jejui Guazu, affluent du fleuve Paraguay, et du río Acaray, affluent du Parana, couvre une superficie de plus de 
$18000 \mathrm{~km}^{2}$ relativement épargnée, alors, par le front de la colonisation paraguayenne et brésilienne qui n'y pénètre qu'à la fin des années 1960 (Figures 3 à 8).

Ce processus de pacification, initié par Pereira, puis relayé par les évangélistes nord-américains des Nouvelles Tribus, dure huit ans : il décime environ la moitié de la population des Aché septentrionaux qui sont spoliés de leur territoire ancestral, déportés et parqués (Melià et al. 1973 ; Münzel 1973, 1974, 2008 ; Smith et Melià 1978). En 1978, la dernière bande nomade capitule. En moins de dix ans, les Aché du Nord ont vu leur espace vital se réduire comme une peau de chagrin : de près de $20000 \mathrm{~km}^{2}$ au début de 1970, il leur faut apprendre à survivre sur 3000 hectares à la fin de la même décennie ${ }^{3}$ !

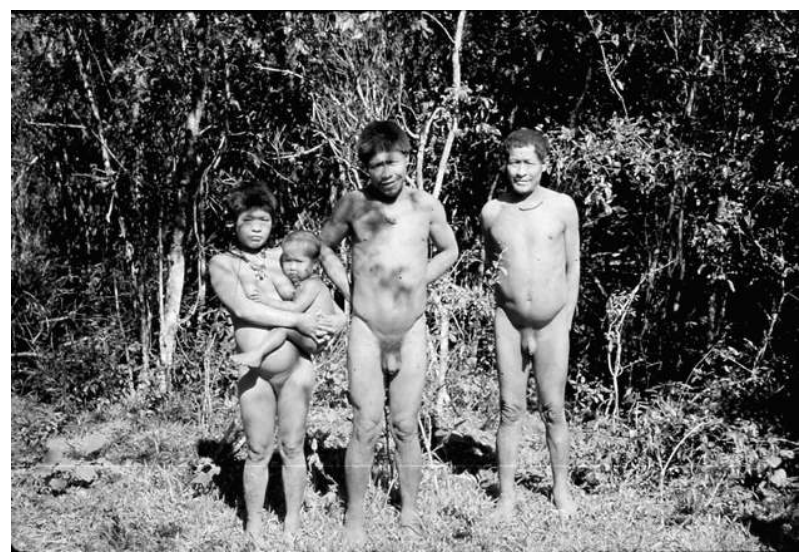

FIG. 3 - Aché purâ à Arroyo Moroti 1962 (mission Cadogan-Colleville, courtoisie de Maxence de Colleville).

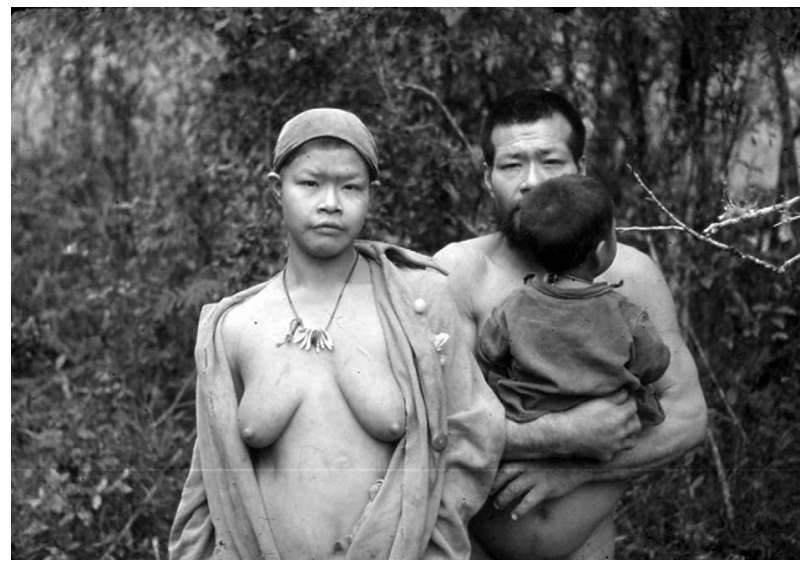

FIG. 4 - Aché purâ (mission Cadogan-Colleville, courtoisie de Maxence de Colleville). 


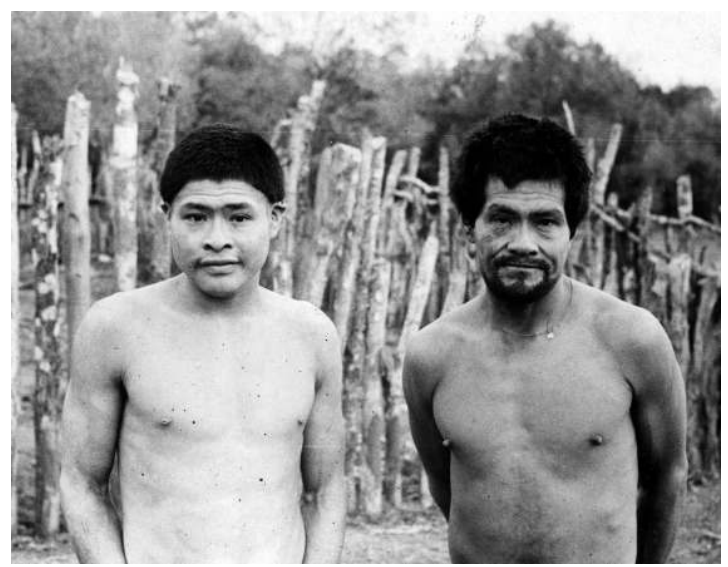

FIG. 5 - Aché purâ (mission Cadogan-Colleville, courtoisie de Maxence de Colleville).

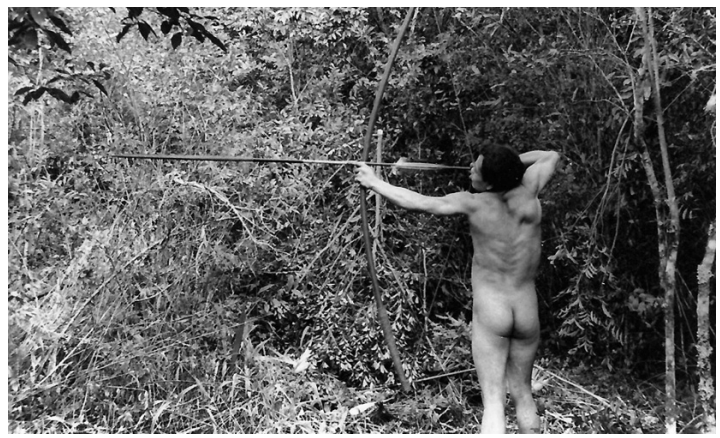

FIG. 6 - Aché wa (mission Cadogan-Colleville, courtoisie de Maxence de Colleville).

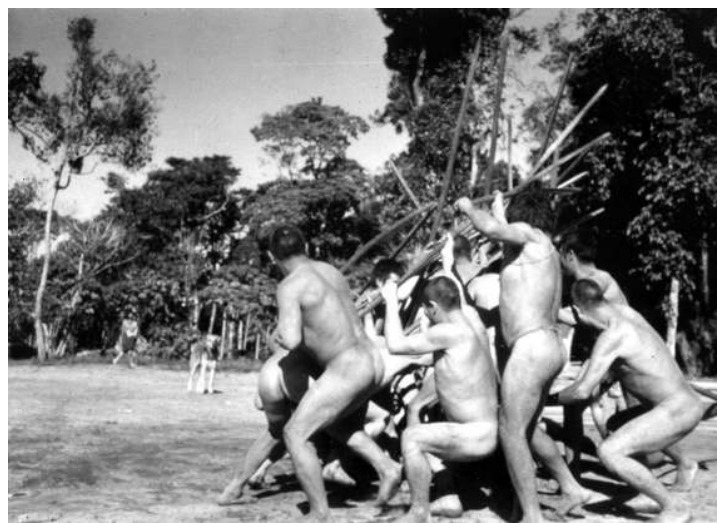

FIG. 7 - Aché gatu du Nord: simulacre de la lutte de massues du tômumbu (d'après un cliché de Chase Sardi donné à l'auteur, Arroyo Manduvi 1975). 


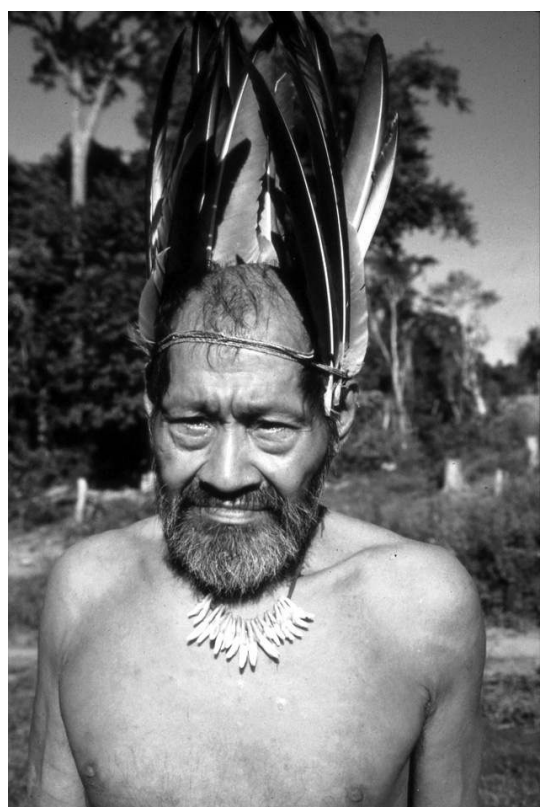

FIG. 8 - Jamo Tatugi $(\dagger$ 1996), membre de la dernière bande du Nord fixée en 1978, maître d'initiation de l'auteur (Arroyo Bandera 1990. Cliché de l'auteur).

\section{Une construction identitaire invisible}

Ce contexte historique tragique, génocidaire, fait de rapports d'évitement avec le monde extérieur ou, au contraire, de contacts violents et de rencontres avec quelques survivants en état de choc, a peu contribué à une ethnographie sereine et approfondie de cette culture. Il a fini par véhiculer et imposer l'image par trop répandue et fallacieuse d'un peuple parmi les plus primitifs des Basses Terres sud-américaines, condamné à l'errance et à la fuite permanente, rétif à tout contact, dépourvu du rire même (Bertoni 1941, p. 17) et d'une tradition orale élaborée (Clastres 1972), timoré voire pusillanime (Hill et Hurtado 1999, p. 95).

Néanmoins, des études ethno-historiques et d'anthropologie économique, commencées parmi les Aché septentrionaux à partir de 1986 (Edeb Piragi 1991 ; 1992 ; 1994), ont permis de révéler un important corpus mythologique, le jypyware jawu, la « parole des ancêtres », - aussi dense et riche qu'insoupçonné qui a commencé à livrer de nouveaux indices et pointer des pistes fécondes d'investigations (Edeb Piragi 1998; 2001). L'analyse comparative de cette tradition orale aché avec les mythologies amérindiennes et l'examen attentif des références qui sont faites à d'autres peuples ont, notamment, permis de renouve- 
ler le débat controversé de leurs origines, toujours dominé par l'idée qu'il s'agissait de proto-guarani ou de gens guaranisés, et de comprendre en particulier que l'on avait trop négligé le rôle des échanges interculturels, comme sous-estimé l'importance des contacts et du dialogue interethnique dans la construction de l'identité aché. Un premier essai d'étude comparative de ce corpus mythologique a contribué à démontrer :

1) que la mythologie aché fait des emprunts inattendus à un fonds culturel d'origine pan-amazonienne - tels «l'homicide à la jambe taillée en pointe », « tapir le cogneur », « l'oiseau du piton rocheux », « l'origine de la nuit », absent de l'horizon mythologique des Guarani du Paraguay et, selon les premiers recoupements, des proches voisins géographiques comme les Gé méridionaux (Kaingang, Xokleng, Guayaña...) (ibid. 2001, pp. 187-191) ;

2) que les Aché sont parvenus à maintenir vifs au cours des siècles, en langue tupi-guarani (ce détail est d'importance), ces thèmes pan-amazoniens très populaires ${ }^{4}$, tout en enrichissant et en augmentant leur tradition orale de pièces originales et inédites avec le reste de la mythologie sud-américaine, à la faveur de leur long isolement culturel dernier, au sein des forêts paraguayennes (ibid., pp. 177-181) ;

3) que la tradition orale des Aché du Nord fournit, donc, des maillons nouveaux et solides pour appuyer la thèse que les lointains ancêtres des Aché ont dû vivre à l'intérieur d'une vaste zone de bouillonnement et d'échanges interculturels située entre les cours moyen et inférieur de l'Amazone et qu'ils ont dû connaître des contacts répétés avec d'autres peuples des familles linguistiques tupi et gé septentrionaux en particulier ;

4) que leur arrivée au sein de la forêt subtropicale serait relativement plus récente que ce que l'on croyait, et que ces « proto-Aché » devaient logiquement s'exprimer en une langue tupi amazonienne. Et ce, contrairement à ce que postule la thèse de la « guaranisation » récente ;

5) sans doute conviendrait-il de parler plus proprement de «cannibalisation » linguistique des Mbyá par les Aché qui ont su s'approprier d'évidents éléments lexicaux mbyá ${ }^{5}$, tout en démontrant une imperméabilité à leurs influences, que ce soit au niveau de la mythologie, la pensée, la psychologie et la religion (ibid., pp. 181-187). Acte de création et d'élaboration farouchement indépendant d'une littérature orale propre, la « parole des ancêtres » se pose, par conséquent, comme l'expression et la marque d'une affirmation identitaire et d'un refus d'assimilation dont on n'avait, jusqu'alors, pas su prendre l'exacte mesure ;

6) c'est la grande révélation du jypyware jawu: malgré des emprunts et un syncrétisme linguistique qui supposent une certaine familiarité avec les Mbyá, les Aché ont su résister activement à la "guaranisation » et se sont construits une identité à partir de ce long processus d'insoumission religieuse, économique et culturelle qui a été un prélude, vraisemblablement, à la rupture politique complète avec les Mbyá-Guarani et à leur enclavement multiséculaire, déjà attesté par 
les sources écrites du XVII ${ }^{\mathrm{e}}$ siècle. C'est ce que nous raconte à sa manière, selon moi, le mythe sur les Guayaki recueilli par Léon Cadogan chez les Mbyá :

Au commencement, les Guayakí et les Mbyá vivaient ensemble sous le gouvernement de Pa'i Rete Kuaray. Un jour les Guayakí apparurent complètement nus à la danse rituelle et Pa'i, furieux, les apostropha en ces termes : Guayaki ; javá mokerá !... et les dispersa à travers la forêt. C'est pour cette raison qu'ils vivent errants et sauvages jusqu'à présent. ${ }^{6}$

Ce mythe prend tout son sens, en effet, si l'on admet qu'il présuppose une coexistence préalable entre les deux groupes et nous parle de la rupture intervenue entre les Aché et Mbyá, dans un second temps, pour des facteurs religieux : la non-observance des règles, une attitude profanatrice - involontaire ou pas comme l'irruption des Guayaki au milieu de cérémonies sacrées. Nous avons signalé ailleurs la volonté manifeste des Aché, au sein même du jypyware jawu, d'« expurger leur tradition orale de références trop explicites à la divinité solaire des Guarani », autre indice accréditant fortement la thèse de quelque sédition confessionnelle intervenue historiquement entre les Aché et les Mbyá (Edeb Piragi 2001, pp. 184-187).

\section{Paradigme anthropologique du chasseur-cueilleur régressif?}

Un extrait de la « parole des ancêtres » met en scène semblable situation de rupture ou de schisme et sans doute n'est-il pas inutile de s'attarder, un instant, sur le mythe des « planteurs de maïs » (littéralement « faiseurs » de maïs) où les Aché du Nord parlent d'eux-mêmes et des futurs Blancs. Ce mythe apporte incidemment, aussi, des éléments d'analyse pour éprouver une thèse fameuse de l'anthropologie américaniste formulée en 1968 par Pierre Clastres sur le caractère régressif de ce peuple.

Ce mythe d'origine évoque un passé lointain où l'humanité est encore indistincte et ne fait qu'une. Les futurs Blancs et les Aché vivent ensemble en bordure de la haute forêt et des prairies naturelles (potreros), et ne sont pas encore différenciés : semi-nomades, ils consomment les épis de maïs encore tendres et verts, qu'ils mélangent aux grosses larves de coléoptère croissant dans le cœur d'une sorte de papayer sylvestre ${ }^{7}$ (chaa en aché), abondant dans la forêt subtropicale (Figures 9 à 11).

La rupture définitive survient parce qu'une frange des humains, les futurs Aché, veut continuer à parcourir la forêt pour leurs élevages de larves, tandis que les futurs Blancs, eux, ont perdu le goût de marcher et de collecter ces larves. Sourds aux exhortations des Aché qui vont recueillir les larves débordant des souches de jacaratia ${ }^{8}$, ils deviennent de vrais planteurs de maïs qu'ils consomment dorénavant bien mûr, puis ils inventent les animaux domestiques à partir des animaux sylvestres ${ }^{9}$. 
Edeb Piragi DYNAMIQUES IDENTITAIRES CHEZ LES ACHÉ (PARAgUay ORIENTAL)

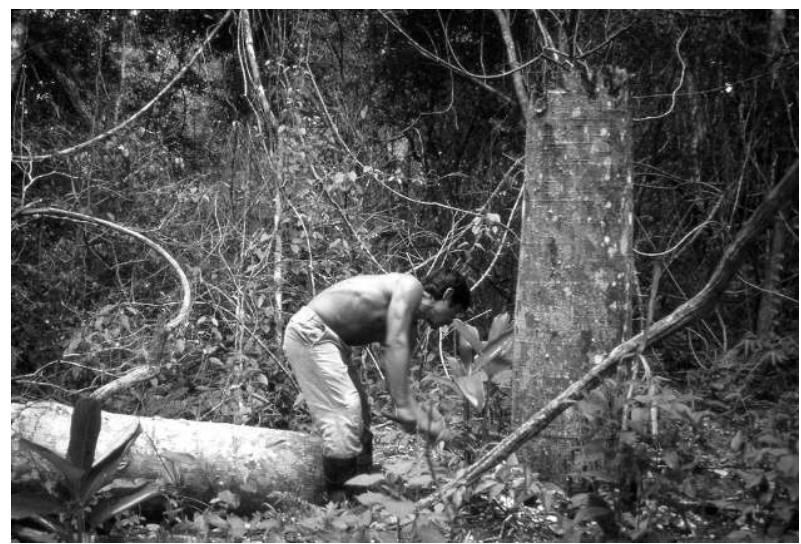

FIG. 9 - La coupe du papayer sylvestre (chaa) (Cliché de l'auteur).

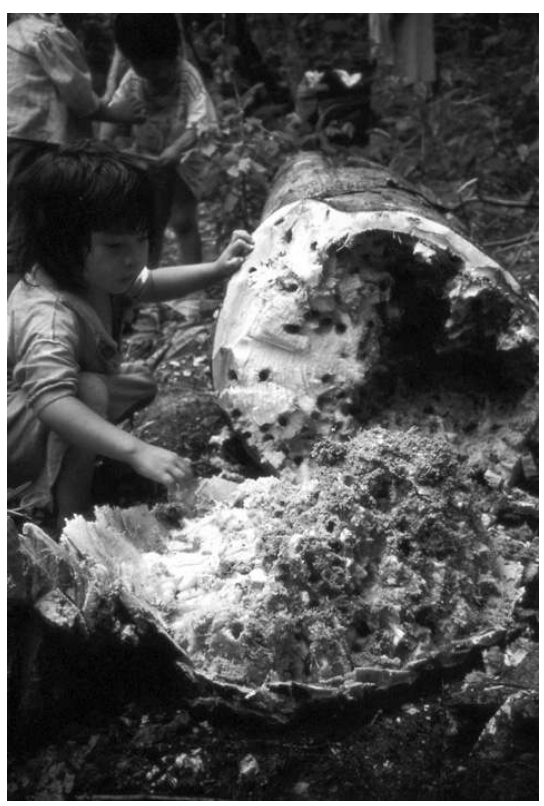

FIG. 10 - Recueil des larves du chaa (Cliché de l'auteur).

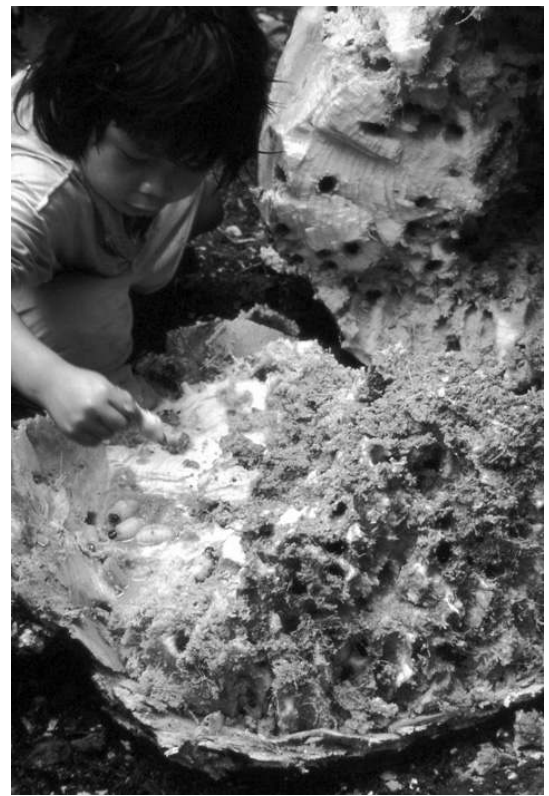

Fig. 11 - Larves du chaa (Cliché de l'auteur). 
Si l'on dépasse les commentaires propres des Aché et une lecture littérale de la trame narrative, est-il exagéré de penser que, sous les traits de la «première humanité indistincte », le mythe décrit - plus fondamentalement peut-être - un peuple bien réel de chasseurs-essarteurs, avec lequel les Aché auraient coexisté pacifiquement dans un premier temps, avant leur séparation fondatrice ? Ce peuple serait identique aux Aché - c'est ce que dit le mythe - parce qu'il consommait, comme eux, les larves du jacaratia spinosa et pareil aux Blancs parce qu'il savait déjà planter le maïs. Ce récit n'évoquerait-il pas, en fait, la rupture historique de l'alliance avec un groupe - à la fois semblable et trop différent - de la forêt subtropicale ? On est tenté de reconnaître les Mbyá-Guarani, référencés, subsumés, dans les premières chroniques, sous l'appellation de Caingua (Caaguas, Kay'gua, Kaingua, Kaa-îhwua...) et décrits comme des horticulteursessarteurs et producteurs, bien avérés, de larves du jacaratialyacaratia:

[Les Kaa-îhwua] établissent des " pépinières » pour l'élevage des tambous. Ils enlèvent une souche épaisse et molle de Dyacaratia à la hauteur d'un mètre du sol. Dans cette pulpe, les tambous se multiplient rapidement ; les Indiens les recueillent et les mangent tels quels ou après les avoir fait cuire au feu du brasier. (Strelnikov 1928, p. 346 ; mes italiques)

Bien que ce mythe confirme la connaissance du maïs par les Aché dont ils consommaient l'épi encore tendre, son contenu et sa lecture possible compliquent pourtant l'hypothèse formulée, en 1968, par Pierre Clastres sur leur passé perdu d'agriculteur, en contredisant la prémisse de cet auteur. L'impossibilité que les Aché du Sud aient jamais pu coexister pacifiquement avec des Guarani et acquérir, d'eux, le terme waté pour désigner le maïs :

Mais un contact amical plus ancien n'aurait-il pu se produire avec les Mbyá-Guarani, permettant aux Aché de connaître le maïs et son nom guarani ? Là encore, les données historiques - rares mais sans ambiguïté - montrent que cette possibilité ne correspond pas du tout aux relations effectives qu'entretenaient Guarani et Guayaki : ennemies jurées, ces deux tribus se faisaient la guerre et s'entredévoraient! (Rappelons que pour les Aché, les Mbyá sont les Machitara : ceux des flèches nombreuses, tandis que pour les Mbyá, les Aché sont des Guayaki : les rats féroces). (Clastres 1968, pp. 51-52)

Pourtant, les Aché du Nord, eux-mêmes, nomment le maïs wache, vache, qui offre - comme beaucoup d'autres termes aché - une plus grande proximité avec le mbyá qui utilise le mot avachi (Cadogan 1992, pp. 32-33 ; Dooley 1998, p. xxvii). Nous l'avons évoqué plus haut, l'influence du mbyá sur la langue aché est indéniable - pour le moins lexicalement - et ce syncrétisme linguistique ne s'explique que, si l'on admet qu'avant l'établissement des relations d'hostilité notoire entre les Aché et les Mbyá, les deux groupes ont connu des périodes de coexistence dont leur tradition orale garde encore, pour peu qu'on sache les voir, quelques traces: le mythe des «planteurs de maïs » est l'un d'eux, 
selon nous, et il en existe d'autres qui font référence à des peuples forestiers voisins avec lesquels il faut composer et cohabiter pacifiquement sous peine de se détruire mutuellement.

En effet, bien que les Aché du Nord désignent génériquement les Guarani par le morphème wachijagi, " possesseur de l'arc », ou wachi tarâgi, " ceux des flèches nombreuses » (machi tarâ en aché wa), ils opèrent encore quelques distinctions entre les Guarani. Le morphème buara ${ }^{10}$ de leur tradition orale renvoie à différents peuples qui correspondraient alternativement - d'après les descriptions et certains traits fournis par les vieux conteurs aché - aux Pai Tavyterâ et aux Ava Guarani, voire aux Mbyá. Par ailleurs, l'ethnonyme Mbyá ${ }^{11}$ existe aussi en langue aché et s'applique, au sein des histoires du jypyware jawu, à un groupe de la forêt avec lequel les ancêtres proches ou plus éloignés entretenaient des relations pacifiques, quoique distantes, et faites de circonspection : il est donc question des (M)byá/(M)bá ${ }^{12}$ tawa rakua, « gens de petite verge ${ }^{13}$, et des (M)ba-kaju, " hommes au teint clair et peuplant les zones riveraines ».

Parmi les groupes méridionaux, les Aché wa connaissaient aussi ce vocable (M)byá qu'ils accolaient à l'autodénomination aché, pour former le syntagme Aché byá et désigner, de la sorte, les autres groupes aché (Cadogan 1968b, p. 28). De manière assez intrigante, l'autre population du Sud, les Aché du Nacunday donnaient aux Guarani le nom générique de (M)byá purâ, "gens différents, étranges» ou "gens non authentiques", syntagme que les Aché du Nord employaient, quant à eux, pour désigner la petite bande d'Aché auparavant inconnue avec laquelle ils firent une rencontre fortuite et leur jonction aux environs de 1925.

Ces indices sémantiques troublants viennent renforcer la thèse selon laquelle, dans la pensée aché, il existe au niveau du langage une certaine confusion d'identité, voire quelque rapprochement ou similitude entre les bandes mbyáguarani et les Aché étrangers : des indices lexicaux qui ne permettent pas de continuer à écarter ou à rejeter, selon moi, la vraisemblance historique d'une proximité sociopolitique entre Aché et Mbyá.

Dans cette perspective d'un passé commun, aussi lointain remonte-t-il, les alliances politiques, voire les échanges matrimoniaux, ont dû largement favoriser l'incorporation mutuelle de membres ou de familles, permettant certain croisement et flux de gènes, soit, pour le dire vite, la fusion des traits ou même une parenté génétique que des études récentes en matière de génome amérindien viennent conforter (Tsuneto et al. 2003 ; Callegari et al. 2007).

Enfin, le contenu même du mythe aché oppose, à mon sens, un démenti à la thèse de la " régression », proposée par Clastres, qui suggère que l'évolution va toujours dans le sens de l'agriculture et qu'une fois les premiers pas de la domestication des plantes acquis, on n'y renonce pas facilement sauf, à son corps défendant, sous la pression de quelque événement négatif ou d'une force supérieure. Dans le cas présent, le discours indigène réfute on ne peut plus clairement 
cette logique affirmant au contraire que les Aché ont pris, volontairement et par goût, le parti de parcourir la forêt et les élevages de larves, qu'ils ont opté sans regret pour le nomadisme les conduisant à abandonner le maïs. Utilisant la terminologie de Clastres, je dirais qu'au travers de leur tradition orale et de leurs attitudes passées et présentes, les Aché montrent qu'ils ne sont pas des horticulteurs contrariés, ni des « régressifs », mais plutôt des « archaïques » assumés. Les témoignages des Aché du Nord, qui ont connu la vie nomade, l'illustrent bien : quoique n'ignorant rien des techniques de plantation du maïs et même du manioc, grâce à d'anciens captifs aché qui avaient pu retourner en forêt après s'être échappés de chez les Blancs, les bandes ont toujours refusé de faire leurs propres semailles, malgré l'insistance de ces évadés. Les anciens se fondaient justement sur ce mythe des «planteurs de maïs » pour rappeler au groupe que là n'est pas leur destin, ni la voie indiquée par les ancêtres, ce que confirmera, à sa manière, l'adoption relativement lente ou discontinue, laborieuse presque, de l'agriculture au sein des communautés sédentarisées (voir plus bas) et ce qui corrobore l'attitude des Aché traditionalistes - anciennes et plus jeunes générations - qui se comportent à bien des égards, trente cinq ans après leur sédentarisation, comme des agriculteurs malgré eux, en restant toujours attachés à la forêt où ils continuent à se ressourcer quand ils trouvent une aire boisée suffisante.

\section{LA TRANSFIGURATION ETHNIQUE ENTRE 1980 ET 2000}

Au début des années 1980, soit deux années après la sortie officielle de la dernière bande nomade en 1978, les Aché du Nord ne possédaient plus l'espace de forêt nécessaire pour continuer à subsister de chasse et de collecte. Ils avaient déjà abandonné leur vie itinérante ${ }^{14}$. Ils n'ont jamais renoncé, certes, à battre les zones boisées proches - leur territoire de jadis passé au domaine public et privé -, mais avec leur fixation au sein de réserves, les activités de ponction ont rapidement changé de rythme, de nature et de forme (Edeb Piragi 1992).

Entre 1980 et 1982, les cinquante familles (199 personnes), fixées à Chupa Pou, ne consacrent plus que $25 \%$ de leur temps, en moyenne, aux activités sylvicoles tandis que ce temps se réduira encore à moins de $15 \%$ en 1987 (Hill et Hurtado 1996) ${ }^{15}$. Ce schéma est déjà généralisé, en 1998, même pour les vingt-trois familles d'Arroyo Bandera ${ }^{16}$ qui vivent aux abords de la réserve écologique de Mbaracayú : en dépit de la proximité de ces 64000 ha de forêt subtropicale, où le peuple aché a encore gardé les droits de collecter et chasser avec des méthodes traditionnelles, les habitants d'Arroyo Bandera ne dédiaient déjà plus que $20 \%$ de leur temps à la chasse et à la cueillette à la fin des années 1990 (Gurven et al. 2002). Que reste-t-il donc, aujourd'hui, de ce mode ancestral d'autosubsistance? 


\section{Un modèle débattu de chasse et collecte subtropicale}

L'économie traditionnelle reposait sur la collecte des végétaux (une trentaine de fruits et trois types de racines sauvages) et de près de vingt-cinq espèces de miel, sur le ramassage des larves (plus d'une vingtaine d'espèces comestibles), sur la chasse au petit comme au gros gibier (daguet, pécari, tapir, carpincho) et, plus occasionnellement, sur la pêche (Edeb Piragi 1992; 2008, pp. 182-184; Edeb Piragi et Kanjegi s. d. b).

La connaissance plus fine des modalités d'acquisition et d'usage de ces ressources sylvicoles est toujours controversée ${ }^{17}$. Si la chasse occupait indéniablement une place centrale dans l'idéologie, la psychologie et l'économie des Aché (Edeb Piragi 1991), qui prisent au plus haut point la graisse d'origine animale ${ }^{18}$, ils n'en étaient pas moins dépendants des produits de la collecte. Les dérivés du palmier pindo (Syagrus spp. , toi'i en aché) formaient même la base alimentaire de ces nomades et la nourriture presque exclusive des principaux événements de leur vie sociale et rituelle (naissance, initiation, deuil, lutte mortuaire...) : moelle concassée ( $k r a k u$ ), bouillie de pindo (bree) obtenue par coction et réduction du liquide amylacé tiré du détrempage à l'eau des fibres du stipe, choux palmiste (tangy) et drupes orangées (pytâ), étaient vitales pour alimenter les malades, les blessés ou les personnes recluses (initié, parturiente, meurtrier...). Quant au üii'/'vii, la fécule tamisée (Figures 14 et 15) et au bree, ils constituaient aussi des ingrédients indispensables pour se sustenter de toutes les parties comestibles d'une dépouille animale (abats, huile des viscères, graisse, moelle osseuse, sang) et, parfois, pour neutraliser la force dangereuse de certains gibiers. Par conséquent, l'exploitation incontournable, durable et quasi-quotidienne, du palmier pindo structurait, de façon plus décisive que la chasse, les stratégies économiques et le nomadisme de ce peuple qui établissait ses grands campements à proximité des palmeraies les plus denses (Edeb Piragi 1992).

\section{Le nouvel « usage " de la forêt}

Aujourd'hui, les Aché du département de Canindeyú parcourent les dernières forêts pour se constituer, essentiellement, des élevages de larves du pindo et du chaa (jacaratia spinosa), collecter le miel de l'Apis melifera (mynga), cueillir les oranges douces et les fruits saisonniers, comme ceux de Jacaratia spinosa, Campomanesia xanthocarpa (wira), Myrcianthes pungens (viju), Rheedia brasiliensis (kuri), Inga marginata (nonga).

La chasse s'est nettement individualisée. C'est seulement lors des grandes festivités communautaires organisées, aujourd'hui, pour l'anniversaire ${ }^{19}$ des jeunes enfants, que les hommes mènent des chasses collectives de quelques jours permettant de rapporter un gibier réduit presque exclusivement, en 2010, à deux 
types d'animaux : le tatou à neuf bandes (Dasypus novemcinctus) et le singe capucin (Cebus apella). Avec un peu plus de chance, les chasseurs peuvent rencontrer le coati (Nasua nasua), le paca (Agouti paca), le daguet (rouge et gris : Mazama spp.) et quelques espèces prisées d'oiseaux sylvestres, comme la pénélope (Penelope superciliaris), le grand hocco (Crax fasciolata)...

Les techniques ont changé aussi. Avec l'apparition du fusil et des lanternes, la chasse d'affût nocturne - le mangullo des Paraguayens - près d'un arbre fruitier ou d'un lieu préalablement appâté de sel s'est également généralisée. Elle permet de tirer les daguets, le paca, l'agouti et, de plus en plus rarement, le tapir. L'usage des armes modernes et des chiens s'est imposé, bien que les Aché n'aient jamais renoncé à fabriquer l'arc et les flèches, seules armes autorisées (théoriquement) à l'intérieur de la réserve écologique de Mbaracayú. Par ailleurs, les enfants et les adolescents s'exercent toujours au maniement de l'arc qui est utilisé lors des grands rassemblements annuels du groupe et de ses joutes intercommunautaires au tir à l'arc traditionnel (aichu pira). Cette arme demeure, à ce titre, un marqueur important de l'identité ethnique et un symbole non négligeable de masculinité. Son usage cynégétique s'est cependant considérablement réduit et, à l'exception de quelques vieux chasseurs, les hommes n'utilisent l'arc que faute de fusil ou de munitions ou en raison de l'interdiction des armes à feu au sein des réserves naturelles ou privées (Figures 12 à 14).

La viande sylvestre est considérée, aujourd'hui encore, plus saine et savoureuse (« parce que, selon eux, elle n'est pas corrompue par la vaccination »), bien que les Aché consomment plus couramment la viande de bovin, de cochons domestiques et de volailles auxquels ils avaient déjà pris goût ${ }^{20}$ durant leur existence sylvicole.

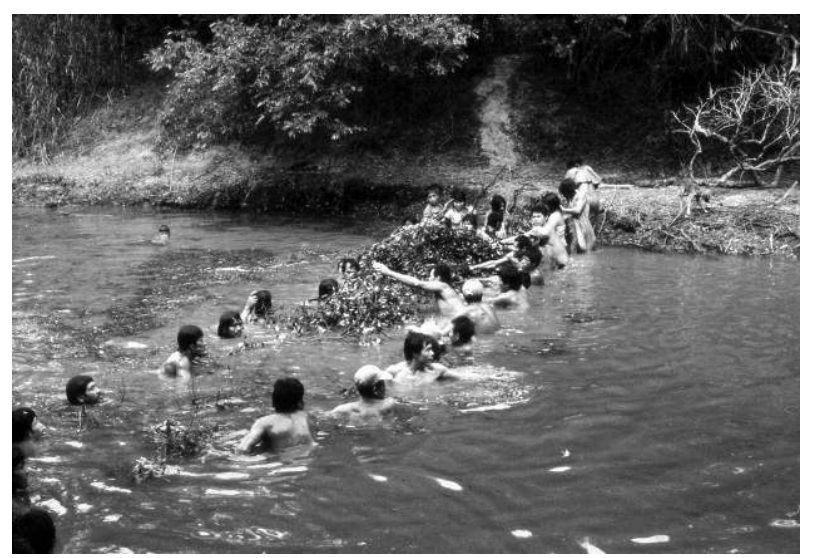

FIG. 12 - Pêche traditionnelle au « barrage roulé », Pira Payjâ (Cliché de l'auteur). 


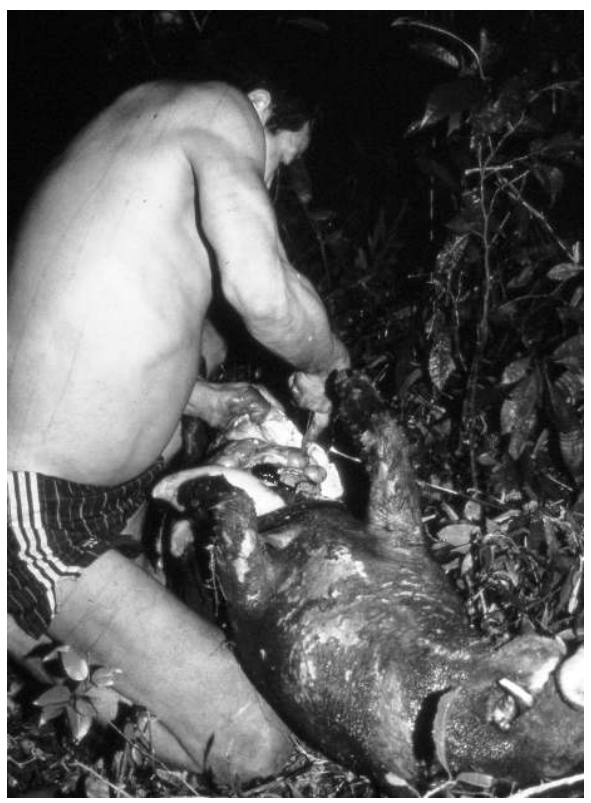

FIG. 13 - Éviscération du grand pécari (Cliché de l'auteur).

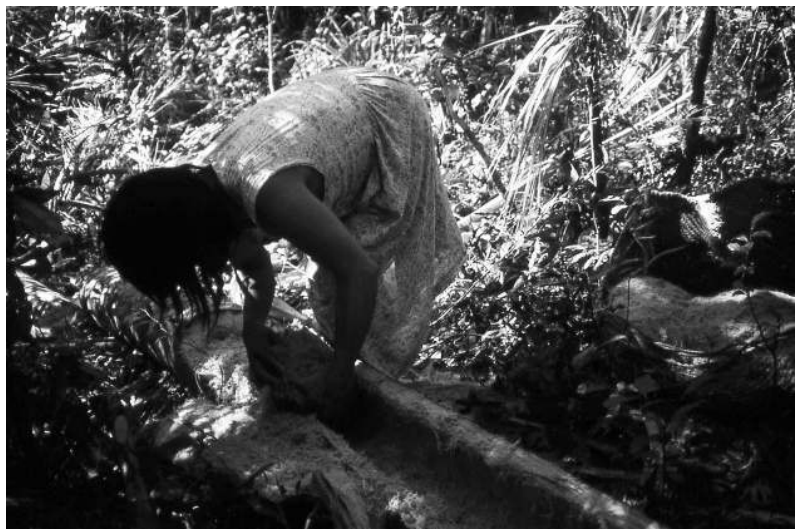

FIG. 14 - Collecte de moelle de pindó (Cliché de l'auteur). 


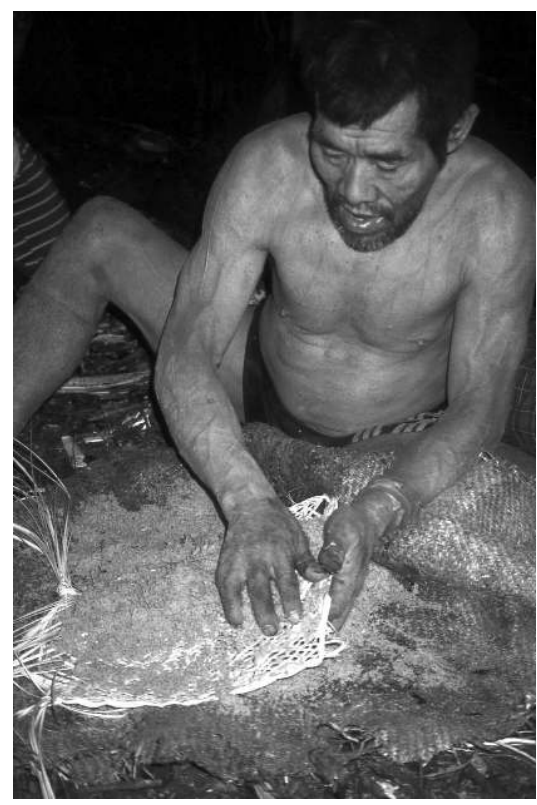

FIG. 15 - Üii « la moelle tamisée » (Cliché de l'auteur).

\section{Entre alimentation et rente}

Depuis le milieu des années 1980, l'alimentation repose principalement sur l'agriculture (maïs, manioc, haricots, arachide, patates douces...), les plantations (canne à sucre, bananes, papayes...) et l'horticulture (pastèques, melon, tomates...): en 1987, les produits agricoles couvraient $65 \%$ des besoins alimentaires des familles de Chupa Pou, complétés pour $10 \%$ par les provisions obtenues dans les boutiques alentour (riz, pâtes, huile, farine, pains, lait en poudre...), et pour 15 à $21 \%$, par la viande sylvestre ou domestique (Hawkes et al. 1987). En 1998, l'agriculture contribue pour plus de $80 \%$ de l'alimentation des familles d'Arroyo Bandera, tandis que $9 \%$ des aliments sont acquis dans le commerce et $11 \%$ seulement provient de la viande sauvage ou d'élevage (Gurven et al. 2002, p. 97).

Pourtant, la mise en route des pratiques agricoles n'a pas été aussi aisée et rapide qu'on le croit généralement ${ }^{21}$. Il a fallu attendre le milieu des années 1980 - soit près de 15 ans après le début du processus de sédentarisation forcée des Aché du Nord - pour que l'agriculture parvienne à dominer, de la sorte, leur nouveau système alimentaire et que les familles plantent des produits de rente comme le coton et le tabac. Ce passage progressif, qualitativement et quantitativement inégal vers l'agriculture, a tenu à deux facteurs principaux : 
1) une nette préférence des Aché - récemment sortis de la forêt ou pas - pour le travail salarié (changa), même sous-payé, qui donne des revenus immédiats et non différés, plus conformes avec la rétribution quotidienne de l'effort individuel ou collectif au sein d'une économie traditionnelle de ponction. L'apparition de nouveaux besoins dans les réserves (outils, vêtements, objets manufacturés...) et la monétarisation ont donc rapidement transformé les Aché en journaliers agricoles ou en manœuvres forestiers sur les champs des paysans et les grandes estancias des environs. Il s'agit d'un phénomène important, sous-estimé par les études socio-économiques, qui fut largement accru par la pression des Blancs et même des missionnaires pour tirer profit de cette main d'œuvre excellente ${ }^{22}$ et bon marché (Edeb Piragi 2008, pp. 194-195). Ce phénomène explique, à mon avis, pourquoi la baisse importante du temps dédié à la chasse et à la collecte entre 1975 et 1985 ne se soit pas traduite automatiquement, chez les Aché du Nord, par une intensification de l'agriculture et des surfaces cultivées. Les individus et les familles ont toujours recours, aujourd'hui, au salariat agricole pour pallier le manque d'argent et les périodes difficiles. Certaines communautés continuent d'obtenir, par ce biais, une ou plusieurs vaches à sacrifier pour une grande fête collective. Si, en 2010, le salariat agricole est cependant en perte de vitesse, cela tient surtout à la baisse constante de l'offre d'emploi sur le marché local, due à la mécanisation des tâches chez les grands et moyens agro-exportateurs de la zone ;

2) corrélativement, les Aché n'ont jamais reçu, ou presque ${ }^{23}$, l'accompagnement technique approprié pour opérer une transition harmonieuse, rationnelle et incitative vers une agriculture sur brûlis ou d'écobuage, étrangère à leur tradition. Durant près de vingt ans, ils ont donc progressivement improvisé et imité les plus mauvais modèles de la paysannerie paraguayenne, précaires et destructeurs du sol et de la forêt, sans bien comprendre l'importance de la jachère et de la rotation des cultures pour augmenter les rendements et réduire l'érosion (ibid., p. 193). L'essart du petit producteur aché épuise le sol au bout de quatre ans en moyenne pour des rendements généralement assez bas (Renshaw et Reed 1990, p. 32). Chez les Guarani, agriculteurs de tradition, cette usure du sol peut ne pas survenir avant dix ans. Le manque de planification est évident. La production n'est pas souvent suffisante, dans une majorité des communautés de Canindeyú, pour couvrir les besoins de chaque famille durant tout un cycle annuel et les périodes " sans » ne sont pas rares. Comme l'observent, à juste titre, Renshaw et Reed (ibid.) à Chupa Pou, le manioc, pourtant cultivable et disponible toute l'année, était imparfaitement planté en 1989. Les Aché le produisaient apparemment plus comme un élément de troc pour solder leurs dettes, auprès de la mission, que comme un moyen d'autosuffisance. Enfin, relevons que les valeurs aché de la générosité, du partage et leur corollaire, l'incapacité de refuser, ont déclenché un phénomène sclérosant d'assistancialisme au sein de la colonie moderne : il n'est donc pas rare que des noyaux conjugaux ou des individus plus oisifs (parmi les 
jeunes générations surtout) se rabattent sur les récoltes ou les réserves d'une famille plus prévoyante et laborieuse. Ce facteur n'a guère incité, ni les uns, ni les autres, à redoubler d'ardeur ou d'industrie.

\section{Le nouveau modèle économique : un bilan mitigé}

L'économie aché oscille actuellement entre deux types contrastés d'agriculture qui coexistent ou se complètent, au sein de quatre communautés au moins : une agriculture mécanisée de rente versus un mode manuel de mise en culture destinée à l'autosubsistance. Cette mixité technologique existe à Chupa Pou qui a reçu un premier tracteur en donation en 1996, ainsi qu'à Arroyo Bandera en 2001. Ce transfert de technologie moderne, improvisé et effectué sans grand discernement, n'a cependant apporté ni le progrès ni le bien-être espéré ; il a contribué à approfondir les contradictions sociales, en créant des mécanismes supplémentaires d'endettement communautaire (maintenance, combustible...), de dépendance économique envers les madereros, de perturbation écologique et de disparités sociales (Edeb Piragi 2008, pp. 193-196).

Depuis la fin des années 1990, trois au moins des sept communautés ont même recours à la location d'une partie des terres (pourtant interdite par la loi 904/81 sur les « communautés indigènes ») pour couvrir les besoins fondamentaux des familles. En 2009, les familles de Chupa Pou qui défrichent et plantent manuellement leurs essarts individuels ont passé un accord avec un exploitant brésilien local pour labourer un terrain de 26 ha et planter du soja, dont les gains sont destinés à la collectivité (médicaments, vivres...).

À Ypetimí, où les essarts d'autosubsistance n'excédent pas un hectare et sont également travaillés manuellement, pas moins de 400 ha sont loués, actuellement, aux Brésiliens de la zone pour la culture mécanisée du maïs et du soja. Le champ communautaire est passé de 80 ha en 1998 à 100 ha en 2010. Les 300 autres hectares se répartissent entre les familles : le lot individuel le plus petit est de 3 ha, tandis que les plus grands atteignent entre 20 à 40 ha et sont essentiellement réservés aux cultures de rente. En 1998, Ypetimí vendait sa production communautaire au Silo de Tuparenda en échange des semences et des machines lourdes pour sillonner la terre et faire la récolte. À présent, la communauté et chaque famille locale reçoivent un pourcentage équivalant à $30 \%$ de la récolte réalisée sur son lopin par l'exploitant agricole brésilien. À Cerro Morotí, les familles ont commencé à louer, au milieu des années 1990, une partie des terres aux éleveurs voisins qui les ont converties en pâturage. Puerto Barra est sans doute la communauté qui maîtrise le mieux l'agriculture mécanisée et en exécute seule les principales tâches, sous l'orientation évidente de la mission évangélique qui a fondé la colonie en 1975. Les quarante familles locales sont parvenues à produire 240 ha de soja transgénique et obtiennent de hauts rendements destinés à l'exportation ( ABC Color 21/02/2010, 01/10/2010 ; Última Hora 06/03/2010), mais cette méca- 
nisation se fait au détriment de l'équilibre environnemental, de la dernière forêt locale et du sol.

\section{La vente du bois versus le "développement durable avec identité "}

La vente du bois est devenue un enjeu économique de taille et le motif principal de conflits, parfois graves, au sein des deux plus anciennes communautés de Canindeyu : Arroyo Bandera et Chupa Pou, surtout, qui détient la plus grande réserve (LINAJE 20/03/2007, 07/05/2007 ; Edeb Piragi 2000 ; 2005, pp. 218-221 ; 2008, pp. 194-199, 211).

Du point de vue du développement impliquant un modèle respectueux de la forêt, des sols et de l'eau, et valorisant les savoir-faire culturels, les communautés qui s'en sortent le mieux aujourd'hui sont celles de Kuêtuvy et Kuêtuwyve (Canindeyú). Ces deux communautés, nées respectivement en 2000 et 2002, ont tiré le meilleur parti des technologies organiques en réduisant la pratique mal maîtrisée du brûlis et en rejetant toujours la mécanisation, pour privilégier, à Kuêtuwyve en particulier, les techniques alternatives telles que le semis direct sans labours, l'usage des insecticides et engrais verts, ainsi que la production écologique d'éponge végétale, de canne à sucre, de ver à soie... Ces communautés s'orientent, chacune à leur manière, vers la valorisation durable des ressources non ligneuses de la forêt (yerba mate, faune sylvicole, miel, fruits, pharmacopée naturelle...).

Une autre source non négligeable de revenus, bien qu'insuffisamment structurée et organisée, est l'artisanat. Les Aché fabriquent la majeure partie des objets et outils traditionnels (paniers de collecte, récipients à miel, arcs et flèches, massue, hache de pierre...) et en ont même inventé de nouveaux pour mieux vendre aux touristes: les sacs de toile végétale traditionnelle aux formes modernes, les figurines animales et leurs ornements pyrogravés, les arcs et flèches miniatures (traditionnellement pour enfants) plus faciles à transporter pour les touristes.

La fonctionnarisation offerte par l'État (instituteurs, promoteurs de la santé...) ou par des ONG (garde forestier...) assure des ressources financières également importantes et vitales pour les jeunes familles.

En résumé, compte tenu du manque de terres et de l'explosion démographique qui ont accompagné la sédentarisation des Aché (Hill et al. 1996, pp. 476480 ; Edeb Piragi 2005, p. 217-218) - dont le taux de natalité annuel, frôlant les $4 \%$, est actuellement l'un plus hauts parmi les vingt groupes du Paraguay -, les défis contemporains de ce peuple tournent, plus que jamais, autour de la protection de ses dernières réserves forestières, une planification rationnelle de l'usage de ses terres limitées et la recherche de débouchés alternatifs. Cela correspond précisément à l'inverse de la tendance dominante actuelle. 


\section{LA DÉCONSTRUCTION IDENTITAIRE ACHE GATU}

\section{Colonie sédentaire versus territoire Ache gatu}

Contrairement à une affirmation aussi répandue qu'inexacte ${ }^{24}$ et qui a fini par s'imposer comme une donnée de base, la communauté aché contemporaine ne peut être considérée, ni ne saurait être présentée, comme une unité sociopolitique sui generis ${ }^{25}$. La création des cinq colonies, où le groupe fut confiné à partir des années 1960, résulte de la politique ethnocidaire menée durant la dictature militaire (1954-1989) contre le peuple aché, systématisant le vol de ses territoires, puis le transfert de ses populations au sein de réserves créées principalement autour ou sous l'influence d'une mission chrétienne : catholique à Chupa Pou (congrégation du Verbe Divin), évangéliques à Cerro Moroti (New Tribes Missions), à Mboi Jagua/Arroyo Bandera (Misión Alemana entre los Nativos del Paraguay) et à Puerto Barra (Hermanos Libres). La configuration territoriale et sociopolitique de ces cinq colonies n'a donc rien de traditionnel si ce n'est la permanence au plus près du territoire d'origine (Figure 2), dans le meilleur des cas, ainsi que le maintien de quelque cohésion sociologique pour les petites unités politiques du Sud, moribondes et excédant à peine trente personnes au moment de la sédentarisation, comme les Aché du Nacunday vivant à Puerto Barra (Alto Paraná) et les Aché wa de l'Yñarô résidant à Ypetimi (Caazapá).

La soixantaine d'Aché de l'Yvytyrusu (Guaira), quant à eux, furent déplacés beaucoup plus au nord-est de leur dernier territoire connu, à Cerro Moroti dans le département de Caaguazú. Une grande partie de sa population s'y concentre encore aujourd'hui et a pu conserver - à défaut de son habitat traditionnel - une certaine unité sociologique. En revanche, le groupe septentrional - le plus important numériquement et dépassant vraisemblablement, au moment du premier contact en 1970, les 700 personnes ${ }^{26}$ - n'a pu se préserver de l'éclatement, ni su se maintenir soudé. Ses familles demeurent, aujourd'hui, dispersées au sein de quatre départements et réparties entre les sept communautés.

Durant une première période confuse et traumatisante de huit ans, familles et individus du Nord ont été principalement déportés - à mesure que les bandes locales sortent de la forêt - vers la Colonia nacional Guayaki (Cerro Morotí). Beaucoup ont tenté en vain de fuir les mauvais traitements physiques et psychologiques, puis les maladies. Certains ont regagné la forêt, d'autres se sont dispersés (et, parfois, ont disparu) sur des estancias du département de Canindeyú. Une trentaine de familles (115 personnes) est parvenue à s'établir entre 1974 et 1977 sur le campement provisoire d'Arroyo Manduvi (Smith 1975; Smith et Melià 1978) dirigé par les catholiques du Verbe Divin, tandis que d'autres ont rejoint une bande nouvellement sortie en 1978 et installée à Mboi Jagua à proximité de la Misión Alemana entre los Nativos del Paraguay. Environ 270 à 300 survivants du Nord ont été fixés en trois points principaux, camps ou colonies constituées à la 
hâte et selon des critères de regroupement obéissant à un plan et une logique plus missionnaire qu'ethnique résultant d'une course entre catholiques et protestants. Les fondamentalistes nord-américains, administrant Cerro Moroti, firent cohabiter des franges aché traditionnellement rivales et s'évitant en forêt. Cette inimitié mutuelle a été renforcée, à Cerro Moroti, en raison de l'accaparement de femmes du Nord par les pisteurs et rabatteurs principaux des Blancs - les Aché $w a$ - qui se comportèrent, de prime abord, en vainqueurs à l'égard des nouveaux arrivants de la forêt. La réduction des Aché sur le territoire étriqué de la mission chrétienne et de ses intérêts propres (dominés par la rivalité entre églises pour la concentration et conversion du plus grand nombre de familles indiennes, la primauté et la diffusion de leurs dogmes...) contribua, par conséquent, à exacerber des lignes de division anciennes, allant du dénigrement jusqu'au conflit armé larvé, en $1984^{27}$, entre Cerro Moroti, où dominent politiquement les Aché purâ (et numériquement ceux du Nord), et Chupa Pou, qui est peuplé presque exclusivement d'Aché du Nord. Ces relations houleuses qui ont perduré durant plus d'une décennie ont achevé de fragmenter le groupe du Nord déchu et affaibli, anesthésié par la déroute et la vision de ses morts. Elles ont également contribué à diluer l'unité et la cohérence politico-territoriale de la catégorie ache gatu, à désarticuler son organisation sociale interne et à provoquer des fissures profondes entre les familles qui se sont disséminées, puis ont fini par se fondre ${ }^{28}$ au sein de colonies éloignées, voire hostiles. Pendant les durs conflits internes de Chupa Pou en 1999, provoqués par la vente du bois qui s'est intensifiée à partir de 1993 (Edeb Piragi 2005, pp. 218-222), il n'était pas rare de disqualifier un opposant qui défendait, avec justesse, le dernier patrimoine forestier des Aché septentrionaux contre la dilapidation, en le traitant de fauteur de troubles et d' « étranger » parce qu'il était originaire de Cerro Moroti où il avait grandi et vécu un temps, oubliant sa véritable appartenance au même tronc septentrional aché gatu et son ancienneté comme habitant de Chupa Pou (en l'occurrence treize ans au moins ). Le plus absurde était que l'offenseur - complice notoire des trafiquants de bois n'avait qu'une ancienneté plus grande d'une ou deux années à faire valoir et, surtout, qu'il venait lui-même du monde des Blancs où il avait grandi après avoir été arraché à la forêt dans sa plus tendre enfance (voir plus loin). Que de tels arguments aient pu porter alors et réussir à déstabiliser la communauté, laissant plus d'un offensé sans voix, et l'ensemble des Aché gatu du Nord sans réaction, révèlent combien les repères identitaires s'étaient dangereusement estompés, à la fin des années 1990, au sein des colonies sous tutelle missionnaire.

\section{L'enfermement}

Depuis la perte des terres ancestrales, il est vrai, le sol de la colonie ${ }^{29}$ est devenu la nouvelle unité territoriale, le repère spatial et foncier que les familles ou les individus utilisent - de gré ou de force - pour s'identifier et dont les modalités 
d'usage sont dorénavant fixées par la collectivité indigène locale. À présent, l'ensemble des familles résidentes et sous la conduite de caciques ${ }^{30} \mathrm{a}$ acquis une indépendance sociopolitique et économique, qui a estompé, voire subverti, l'organisation sociale et territoriale ache gatu (voir infra note 25). Dans l'agenda de priorités de cette nouvelle communauté, prévalent les besoins les plus prosaïques et immédiats de ses habitants. Les familles locales se sentent de moins en moins les dépositaires d'un patrimoine écologique, pourtant dérisoire et fragile, que tout Aché gatu devrait préserver et transmettre aux générations futures. Jusqu'au début des années 2000 , les dernières possessions de forêts locales ont été traitées comme le bien exclusif de chaque colonie et les résidents pouvaient en disposer librement, sans avoir de compte à rendre au groupe d'origine, ni à l'ensemble ethnique.

Ce sentiment dominant d'une nouvelle appartenance communale, oublieux du territoire ancestral et de l'ordre sociopolitique traditionnel, a été renforcé avec la nouvelle législation indigéniste de $1981^{31}$, laquelle a doté, pour la première fois, les communautés indigènes du Paraguay d'une personnalité juridique leur permettant, enfin, de recevoir les titres de propriété pour les terres qu'elles occupaient de facto, depuis la perte de leurs territoires qui a été accélérée durant la première moitié du $\mathrm{Xx}^{\mathrm{e}}$ siècle. Il n'est pas exagéré de dire qu'avec cette nouvelle figure légale qui, par un effet pervers, a approfondi la fermeture des collectivités indigènes sur les frontières dessinées par les missions chrétiennes et l'État paraguayen depuis la fin $\mathrm{du} \mathrm{XIX}^{\mathrm{e}}$ siècle, les cinq colonies aché se sont détournées - jusqu'au début des années 2000 - des intérêts ethniques objectifs et de l'unité du peuple aché : notion qui aurait impliqué des revendications supra communautaires, affirmant leur identité culturelle, la défense active des droits collectifs sur l'ensemble d'un territoire ancestral commun, par exemple. Ce cloisonnement du groupe en communautés politiquement indépendantes, défendant essentiellement des prérogatives sur quelques lots de forêts attenantes, a favorisé puis précipité - à partir de la fin des années 1980 -, la braderie de son dernier patrimoine écologique (Edeb Piragi 2005 ; 2008). Cette même compartimentation a profité, à partir de 1987, au lobby écologiste privé (Nature Conservancy des États-Unis et la FMB du Paraguay) qui entendait créer la réserve écologique de Mbaracayú au cœur du territoire ancestral des Aché gatu du Nord. Ce lobby vert n'a pas cherché à engager de pourparlers avec l'ensemble des mandataires légitimes du groupe septentrional aché gatu ${ }^{32}$. Il a seulement traité avec quelques leaders ne représentant, tout au plus, que les deux communautés désorganisées, divisées et mal informées, de Chupa Pou et Arroyo Bandera ${ }^{33}$.

\section{Le nouveau poids des " clans familiaux"}

La création de la communauté moderne inaugura l'un des changements les plus perturbateurs pour cette ancienne société nomade : une concentration per- 
manente des familles, inconciliable avec son modèle traditionnel d'occupation spatiale et de dispersion sociologique (Edeb Piragi 2008, pp. 188-191). La population de la communauté moderne avoisine, aujourd'hui, entre 150 et 550 habitants ${ }^{34}$, formant des conglomérats de 35 à 100 maisonnées, difficilement gérables politiquement, où les tensions de vie sont devenues de plus en plus pesantes et où le tissu social s'est fragilisé. Dans un passé traditionnel, la dissémination prolongée ou occasionnelle des familles élémentaires en unités productives minimales (deux à trois couples) et la circulation fluide des individus ou des familles nucléaires entre les bandes constituaient autant de principes structuraux qui permettaient d'anticiper ou de dénouer les conflits. Et, surtout, l'écheveau intriqué de la réciprocité généralisée, liée aux règles de traitement des animaux et des obligations tissées par les multiples formes de parenté symbolique (jary, bykuare, paternité multiple...), maintenait les liens d'une coopération indéfectible entre les foyers d'une bande locale, puis entre toutes les bandes du groupe aché gatu.

Avec les grandes concentrations de population sédentarisée, le centre de gravité sociopolitique s'est déplacé sur les arrangements conjoncturels et changeants des familles résidentes, regroupées, à présent, en factions ou clans : ces groupes de familles apparentées ou unies par des liens d'amitié et d'affinité dépendent de leaders naturels qui ne taisent pas leurs désaccords avec les dirigeants officiels de la communauté et forment des coalitions mouvantes, ponctuelles, autour d'enjeux parfois plus prosaïques et intéressés qu'en forêt. Ces groupes de pression familiaux ont fini par provoquer une certaine instabilité sociopolitique et une difficulté à construire un consensus majoritaire solide, y compris sur des thèmes d'intérêt vital pour la collectivité comme la régulation de la vente du bois, le contrôle et la répartition des gains, la planification du travail collectif, la recherche de débouchés alternatifs viables, les négociations avec l'extérieur... Les crises socio-économiques aigües qui ont conduit, à partir de la décennie 1990, à des changements cycliques de « caciques » à Chupa Pou et à Arroyo Bandera, en sont l'indicateur le plus manifeste. Ces factions ou ces clans familiaux peuvent paradoxalement - mais seulement en apparence, car cela renvoie à une caractéristique psychosociologique fondamentale qu'ont su préserver les Aché - renoncer à défendre ou à imposer le point de vue de leur majorité ${ }^{35}$, lorsqu'ils se heurtent à l'intransigeance de secteurs minoritaires plus obstinés (iuieiâ), voire agressifs (prajâmbuchâ). Empêcher la fracture collective et maintenir quelque cohésion à l'intérieur de la communauté représentent en quelque sorte le dernier rempart. Il n'a pas suffi durant le schisme de Chupa Pou.

\section{LE RETOUR DES « CAPTIFS » DU BLANC : LES BERU YMAVEGI}

Le moins que l'on puisse dire est qu'il est peu aisé, pour le non-spécialiste, de radiographier un groupe aussi secret, de tenter d'identifier les tendances et les 
courants qui coexistent au sein d'une même communauté, de mesurer leur poids politique et leur représentativité au sein de l'ensemble ethnique. Peu enclins à extérioriser leurs désaccords internes devant les Blancs, les Aché répugnent à désavouer publiquement - même s'ils en sont excédés - celui ou celle qui parle en leur nom sans les avoir consultés ${ }^{36}$ : une caractéristique psychosociologique et culturelle qui a joué longtemps contre les communautés et le groupe. Qui, au sein de la société paraguayenne, en effet, imaginerait qu'un Aché puisse se désigner porte-parole de son peuple sans avoir été mandaté pour le faire et puisse exprimer, dans un important quotidien paraguayen ou sur les ondes, des idées que beaucoup de familles ne partagent pas ? Comment concevoir qu'un Aché puisse signer un accord de coopération institutionnel sans le consentement dûment informé de sa communauté (LINAJE pronunciamiento du 06/12/2006) ou signer un pouvoir écrit aux avocats de puissants madereros pour mener - au nom d'une colonie qui l'ignore - des actions juridiques qu'elle désapprouverait (Edeb Piragi 2008, pp. 198-199) ? Coutumiers du fait le sont, indéniablement, certains beru ymavegi (" ceux qui furent élevés par les Blancs »), anciens captifs, arrachés enfants à la forêt, et qui ont grandi au sein de familles paraguayennes. Les Aché les appellent aussi les « enfants du Blanc» (beru ray) ${ }^{37}$. Ils sont revenus au cours des décennies 1980 et 1990 grâce aux missionnaires catholiques du Verbe Divin qui ont entrepris, depuis 1975, de les retrouver pour les restituer à leurs vraies familles. L'entreprise noble et nécessaire s'est révélée catastrophique dans le contexte d'une dépendance économique accrue des communautés aché, d'une déstructuration du système sociopolitique traditionnel et d'un affaiblissement des mécanismes collectifs du contrôle social. C'est le phénomène qui a le plus brouillé les contours de l'identité aché et compliqué la bonne compréhension de la problématique aché et de sa dynamique moderne. Force est de constater que quelquesuns de ces rescapés, ignorant la langue et les usages aché à leur retour, mais ayant intériorisé les préjugés racistes des Paraguayens sur les Guayaki, l'importance de l'argent et la valeur marchande des biens, se sont conduits, et ce jusqu'à présent, comme les alliés des Blancs et les complices directs des négociants de bois. Quelle est leur importance numérique ? D’après mes chiffres, trente six Aché du Nord sont revenus ou ont été localisés par leurs familles ${ }^{38}$. Accédant rapidement, pour quelques-uns, à la charge de "cacique » au sein des communautés aché, en un laps de temps de trois à six ans parfois (Edeb Piragi 2008, pp. 196-199), et l'une d'entre eux ayant occupé la présidence de l'institut national de l'Indigène (INDI) en 2008 , on peut affirmer que leur influence politique est inversement proportionnelle à leur nombre. C'est bien le facteur décisif qui a pesé, et qui pèse encore, sur la destinée du peuple aché. Pour le meilleur, parfois, si l'on se remémore la trajectoire exemplaire, au sein même du militantisme indigène au Paraguay, du professeur Luis Duarte Vazquez Kuchîngi, décédé en 2002 (Edeb Piragi et al. 2002) ou si l'on songe à un ou deux autres beru ymavegi qui ont gagné durablement le respect des couches «traditionnalistes » et sont devenus des figures 
politiques marquantes de la fédération aché créée en 2008 (Edeb Piragi 2008, p. 219 note 38). En dehors de ces exemples, les beru ymavegi ont plutôt été parmi les principaux instigateurs, acteurs ou partisans de la braderie du bois à Chupa Pou en 1988, puis de la dilapidation, entre 1993 et 1999, d'une portion des 6534 ha de la dernière et plus grande réserve forestière de la nation aché (Edeb Piragi 2005, pp. 219-221). Cette exploitation irrationnelle du bois, préjudiciable à maints égards pour le groupe, s'est intensifiée entre 2006 et 2007. Ce fut à ce moment-là que Chupa Pou fut placée sous les feux des projecteurs par la presse écrite et télévisée paraguayenne (notamment dans les quotidiens $A B C$ color 02/09/2006, 19/10/2006, 15/02/2007, 03/03/2007, 22/03/2007; Última Hora 23/02/2007, 28/02/2007, 21/03/2007, 24/03/2007; La Nación 18/02/2007, 21/03/2007, 22/03/2007 etc), littéralement déchaînée contre la communauté et les excès de certains de ses membres, rebelles aux lois environnementales. Cette médiatisation, parfois outrancière, a renvoyé à l'opinion nationale indigène et non indigène, une image assez déformée et négative du peuple aché (LINAJE comunicado público 20/03/2007).

L'association de communautés aché (ACA) créée, en août 2004, à l'initiative de la mission catholique de Chupa Pou, est précisément une organisation dominée par les beru ymavegi et présidée par l'une d'entre eux. Symptomatiquement, l'ACA n'a servi jusqu'ici qu'à minimiser l'ampleur de la destruction écologique de Chupa Pou et tenter de la justifier, aux yeux de l'opinion publique, avec des arguments spécieux et parfois contradictoires (ABC color 22/03/2007; Última Hora 11/04/2007). Ces déclarations seront commentées et démenties - au sein du groupe - par des anciens et des familles de Chupa Pou, ainsi que des membres du conseil directeur de l'ACA, traditionalistes issus des autres communautés. La plupart d'entre eux sont allés jusqu'à stigmatiser l'opacité de son fonctionnement et de ses objectifs, reprochant notamment à la représentante légale de l'ACA de ne pas les consulter avant de s'exprimer, dans les médias, au nom du peuple aché. Certains ont fini par renoncer à leur charge pour participer à la création de la fédération aché (FENAP) en août 2008. L'ACA est loin d'être représentative des diverses tendances identifiables au sein des six communautés qui l'ont intégrée officiellement. De nombreux clans familiaux n'ont jamais reconnu cette association, critiquant le manque de discussions démocratiques qui a marqué et miné sa création. Sa présidente n'en a pas moins occupé les pages des quotidiens paraguayens et les tribunes d'opinion, où elle fut présentée alternativement comme « ministre des relations extérieures du peuple aché » (Última Hora 08/03/2006) ${ }^{39}$ ou « présidente de la nation aché ${ }^{40}$.

Le fait serait sans doute anecdotique et risible (pour les Aché qui préfèrent en rire effectivement), si cette présence médiatique et la monopolisation de la parole par cette figure indigène n'avaient pas fini par rendre opaque la complexité de la problématique aché et invisibles les différences de vues et d'opinions développées à l'intérieur du groupe. Cette présence médiatique a également donné à n'enten- 
dre qu'une voix favorable aux groupes de pression (écologiste, missionnaire...) qui, eux, la plébiscitent tout en violentant les droits de son peuple sur son territoire ancestral. Enfin elle a également servi de faire-valoir à l'indigénisme catholique qui couvre les agissements condamnables du missionnaire à Chupa Pou, depuis le milieu des années 1990, et qui est pleinement complice de l'impunité dont il a joui jusqu'à présent (LINAJE, 20/03/2007).

La présidente de l'ACA est devenue le 20 août 2008 la première autochtone au Paraguay à accéder au poste de ministre titulaire de l'institut national de l'Indigène (INDI). Pouvait-on vraiment croire encore, comme beaucoup l'affirmaient alors, qu'il s'agissait d'une grande victoire du peuple aché et de sa cause ?

\section{La présence missionnaire}

Acteur déterminant de la création de la communauté aché moderne, la mission chrétienne omniprésente au sein des colonies a, elle aussi, influé - pour le meilleur et pour le pire - sur le processus de sédentarisation du groupe et continue à conditionner son présent comme son devenir. Aujourd'hui, à l'exception notable de Kuêtuwyve qui refuse cette présence religieuse, les six autres communautés sont « accompagnées » par une, voire plusieurs, congrégation(s) chrétienne(s), appartenant à neuf ordres religieux dont huit églises évangéliques (Edeb Piragi 2008, pp. 209, 214-215). Cet accompagnement se traduit par des visites régulières en vue d'assurer la formation théologique, par une assistance surtout éducative et sanitaire, ainsi que par une présence permanente - depuis le milieu des années 1970 - de la congrégation catholique du Verbe Divin à Chupa Pou et de l'église évangélique des Frères Libres à Puerto Barra.

Quarante ans de conquête spirituelle menée, inlassablement, par les congrégations évangéliques ont sapé les fondements des croyances, des valeurs et des liens profonds qui reliaient les Aché nomades avec le monde de la forêt et ont désarticulé leur mode de gestion rationnel et respectueux de la biodiversité. Avec la présence des pasteurs évangéliques non aché, puis aché, les anciens ont renoncé à leur rôle d'éducateur et arrêté de transmettre de précieux savoirs sur la faune et la flore, comme les règles de l'entente avec les animaux. Ils ont cessé de narrer la «parole des ancêtres », où sont révélés les codes moraux et les valeurs qui régissaient les relations sociales du monde de la forêt (Edeb Piragi 2001). La coupure spirituelle avec la forêt ancestrale a entraîné une évolution des perceptions et des utilisations du milieu forestier, destructrices et contradictoires avec l'éthique nomade, passant par la conversion anarchique de forêts en champs et pâturages, par la vente du bois et par une mécanisation agricole incontrôlée.

Les catholiques du Verbe Divin, qui ont tenté d'éviter le prosélytisme religieux (Alejandro Pytel, cité in Escobar 1988, pp. 171-179), ne sont pas en reste, eux non plus, quant aux effets déstabilisateurs de leur présence. Depuis 1991, la mission de Chupa Pou a brillé par sa participation active - plus exactement par sa compli- 
cité - dans l'exploitation et le pillage de la réserve forestière (Edeb Piragi 2000, 2008 ; LINAJE 20/03/2007). Par ailleurs, grâce à ses fonctions de responsable de l'éducation aché auprès du ministère de l'Éducation et de la Culture (MEC), le missionnaire du Verbe Divin a mis à profit les réunions d'instituteurs et de leaders pour aider à structurer, en août 2004, l'ACA chapeautée par les beru ymavegi, ses alliés notoires à Chupa Pou. Les ingérences politiques du Verbe Divin dans les affaire internes du peuple aché devinrent évidentes lors de la deuxième assemblée de l'ACA à Puerto Barra (2006), où le verbita pesa sur l'ordre du jour et dirigea les débats devant un auditoire de leaders et d'instituteurs visiblement mal à l'aise.

\section{LA RÉSILIENCE DE LA SOCIÉTÉ ACHÉ}

Cette combinaison kaléidoscopique de traits sociopolitiques turbulents et de situations économiques chaotiques augurait, en 1999, un avenir très difficile et incertain pour l'ensemble des cinq colonies du groupe. Le peuple aché a su pourtant opérer, dès le début de la décennie 2000, un réveil salutaire qui le conduisit à se fédérer en 2008. Ce sursaut a nécessité suffisamment de clairvoyance et d'opiniâtreté de la part de ses franges les plus conscientes pour parvenir à dialoguer, à reconstruire leur identité éclatée et à défendre les droits collectifs d'une nation en soi et pour soi. Afin de comprendre comment ce retournement fut possible, il convient de considérer un ensemble d'indicateurs sociaux et d'indices dans lequel perçaient, en dépit des forces acculturatrices qui l'assiégeaient de toutes parts, les signes de vigueur de la société et de la psychologie des Aché.

\section{La communauté des croyants}

Ce n'est pas le lieu de chercher à analyser en profondeur, ici, les modes de pénétration ou les raisons du succès des églises évangéliques auprès des Aché qui sont presque tous convertis au christianisme, adeptes de l'IEU (Iglesia Evangélica Unida) et pratiquants assidus du culte dominical. On doit souligner que, malgré son caractère acculturateur évident, le message évangélique n'a été reçu et entendu que parce qu'il était aussi en syntonie et compatible avec maints éléments de leur culture traditionnelle et de leur vision du monde. Ce message a donc pu être réinterprété et progressivement digéré, intégré en s'enracinant dans la tradition orale et les croyances propres ( $k r e i$, le souffle vital, en particulier), grâce notamment au chant et à la prédication sur le mode du témoignage personnel qui sont des véhicules puissamment communicatifs et porteurs au sein de cette culture.

Par ailleurs, dans le contexte peu rassurant de la communauté moderne, où la réciprocité généralisée est devenue impossible et où la cohésion sociale s'est 
affaiblie, le culte religieux avec son assemblée de croyants a permis de recréer l'illusion d'un réseau de solidarité où la communion, le dialogue, l'empathie vis-à-vis des malades et des plus nécessiteux, réactualisent les rites collectifs de la forêt, ceux menés particulièrement par les anciens et les femmes enceintes ${ }^{41}$, en vue de guérir ou de sauver un membre de la bande (qui est malade, blessé ou qui a été mordu par un serpent...).

Le groupe compte plus d'une vingtaine de catéchistes et prêcheurs réunis au sein de l'église évangélique unie (IEU). Ils ont un programme à la radio de Curuguaty (Canindeyú) les samedis de $12 \mathrm{~h} 00$ à $13 \mathrm{~h} 00$, au cours duquel ils font entendre une voix positive et inclusive, critique face aux abus perpétrés contre les communautés. Il ne faut certes pas minimiser les aspects négatifs de ce phénomène religieux ou de son détournement : il a notamment favorisé la démission et la déresponsabilisation des collectivités qui ne sont pas ou plus « en prise » avec la réalité, leur apprenant à s'accommoder de leur situation présente, à accepter, endurer et pardonner l'inacceptable, comme la corruption de certains « caciques » ou de membres peu scrupuleux, les tromperies dont pâtissent les collectivités, etc. Que la religion puisse devenir un mode de pouvoir, cela n'a pas échappé, non plus, à certains pasteurs aché et leaders charismatiques - adeptes des New Tribes Mission surtout - qui en usent pour influer sur la majorité des familles et des individus et tentent de contrôler leur voix et leur vote lors des assemblées communautaires. Ce fut parfaitement clair lors des dernières élections des représentants légaux à Kuêtuvy, en 2009, où les fidèles du temple ont cherché à peser sur les affaires politiques de la collectivité. Ce phénomène est encore relativement récent dans les communautés aché. Le « cacique » principal s'est maintenu à son poste grâce à un songe (le rêve est important chez les Aché) et à l'annonce de châtiments divins en cas de démission prématurée. Ne nous y trompons pas. Le " cacique » ne fut sauvé que grâce à cette force ou sagesse qu'ont su garder les Aché et les clans majoritaires - certes chrétiens, mais non acquis à sa personne de privilégier, en dernière instance, l'harmonie du groupe, d'éviter la cassure sociétale, d'attendre ou de temporiser pour mieux rebondir.

Bien que l'évangélisation menée par les pasteurs fanatiques des New Tribes Mission ait alimenté et enflé gravement les conflits intercommunautaires de la décennie 1980, elle n'a pas débouché, chez les Aché, sur des divisions religieuses ou des conflits confessionnels. Au contraire. La conversion au protestantisme ne s'est réalisée et finalement imposée que parce qu'elle était vécue comme un recours - en concordance avec leur idéologie - contre la déliquescence du corps social : le temple, les réunions nocturnes et le culte dominical sont devenus, pour l'ensemble des familles traditionalistes qui ont connu la forêt et pour les jeunes générations qui n'adhèrent plus aux normes ou aux valeurs de ce passé, l'un des derniers lieux et moments privilégiés pour réapprendre à se rencontrer, à dialoguer, à chanter et vibrer à l'unisson, trouver des repères communs face à une crise du sens. 
Les Aché sont capables de revirement ou volte-face étonnant et ont démontré, depuis longtemps, que leur rapport à la religion des Blancs et aux missionnaires non indigènes est complexe et que la rencontre avec l'autre se construit dans la durée et la quotidienneté, mais selon leurs règles. Deux ordres religieux l'ont expérimenté à leurs dépens : les New Tribes Mission qui ont été définitivement expulsés de Cerro Moroti en 1990, après plus de vingt années de présence ininterrompue, et le Verbe Divin qui fut chassé de Ypetimi en 2004, après plus de huit ans d'« accompagnement » continu ${ }^{42}$.

\section{La réconciliation ethnique}

Traditionnellement, les quatre groupes aché se considéraient Aché gatu, " gens de référence », "être humain sui generis », et dépréciaient les autres groupes définis négativement comme Aché : ni Blancs ni Guarani, certes, mais pas complètement Aché ! À cet égard, le terme purâ que les Aché du Nord appliquent aux Aché de l'Yvytyrusu est assez révélateur et ne prête pas à confusion $^{43}$ : «gens nous paraissant », une " copie non conforme » en somme, un ersatz d'Aché presque. Pourtant ce groupe sociopolitique lui était le plus proche et apparenté, la séparation ne s'étant produite qu'au début des années $1940^{44}$ et scellée définitivement qu'avec le tracé de la route menant d'Oviedo à Puerto Stroessner dans les années 1960.

Les Aché wa, quant à eux, étaient convaincus que leur endurance en forêt était bien supérieure aux autres et qu'ils étaient les plus véloces de tous les Aché. Bien après la sédentarisation, ils confieront aux Aché du Nord qu'ils puisaient un peu de cette force de l'ingestion du fruit de l'alecrin (Holocalix balansae) que les autres groupes aché craignaient de consommer. Ils tiraient partie de leur avantage physique pour pister et traquer les autres bandes du Nord qu'ils mettaient en fuite, afin de leur voler des femmes et faire provision, à l'occasion, de graisse humaine. Ces Aché wa furent - quels qu'aient pu en être les motifs (tromperie des Blancs, esprit de revanche...) - les pisteurs zélés des Blancs pour traquer et précipiter la sortie dramatique et létale des dernières bandes en isolement volontaire. De cette période tragique, les Aché du Nord ne semblent pas avoir conçu de rancœur contre les Aché wa, ni contre les Aché purâ, pour leur collaboration avec les Paraguayens et les missionnaires. Ce sont même les deux groupes avec lesquels les Aché gatu septentrionaux se sont relativement le plus mélangés et mariés depuis la sédentarisation : en 1989, 15\% des alliances matrimoniales étaient nouées avec un membre de ces deux groupes (Hill et Hurtado 1996, p. 56).

Les Aché du Ñacunday ne semblent pas plus distincts ou plus éloignés linguistiquement et culturellement de ces derniers que les Aché wa, mais ils maintenaient, il n'y a pas si longtemps, une distance prudente avec les Aché gatu du Nord et de l'Yvytyrusu. Deux mariages, seulement, avaient été noués avec les 
membres du Nord jusqu'en 1994. Les relations intercommunautaires étaient parasitées, il y a peu encore, par la rivalité, les moqueries, quelques manifestations de supériorité ou de dédain vis-à-vis de l'autre, quelques particularismes culturels. Les derniers vieux aché gatu du Nord soulignaient, avec malice, les tics de langage des Aché du Ñacunday, leurs peintures faciales ridicules ou « sans grande signification » (japo rei), leurs piètres qualités de chasseurs (tatu kuaraiâ : tatu muje, "incapables de pister le tatou: seulement bons à utiliser le piègeassommoir »), leurs arcs et leurs flèches mal proportionnées (wachi kytâ buchâ, "leurs flèches sont trop courtes et de section trop grosse»; rapa beta akua, " l'extrêmité des arcs est pointue comme un labret ») ou leurs manques d'aptitudes à l'archerie (wachi o iâ « leur flèche ne s'élève pas »). Les anciens stigmatisaient de la sorte, la coutume que les Aché du Ñacunday avaient de flécher les singes capucins du haut des arbres, tandis qu'eux-mêmes, ceux du Nord, forçaient et fléchaient, du sol, les plus gros individus qu'ils savaient repérer et isoler au sein d'une troupe en débandade. Ce sont les vieux qui continuent à raconter ces choses-là pour faire, toujours, rire en aparté.

À présent, les familles circulent mieux et plus rapidement entre les diverses communautés, elles ont appris à se connaître, à chasser et à collecter ensemble, à partager et à échanger leurs propres connaissances, à respecter leurs différences. Les quatre groupes aché gatu sont réconciliés et forment désormais une nouvelle unité sociopolitique, une nation. Plus d'une dizaine de mariages ont, d'ores et déjà, eu lieu ces dernières années entre Aché gatu du Nord et Aché gatu du Nacunday.

\section{L’unité politique versus l'hétérogénéité linguistique}

En dépit de la dévitalisation sociopolitique et territoriale de la catégorie ache gatu, évoquée plus haut, ni l'acculturation, ni l'érosion linguistique n'ont suffi pour entamer le sentiment d'attachement et d'identification des Aché du Nord à leur dialecte. Cela peut étonner si l'on songe qu'avec la disparition progressive des derniers sages du groupe et l'envahissement quotidien du guarani, des pans non négligeables de leur culture se sont écroulés et que la langue maternelle a évolué, s'est transformée, parfois aussi mélangée et appauvrie. La défense de la langue maternelle s'est pourtant révélée comme un point d'ancrage fondamental suffisant pour que les Aché du Nord résistent - durant 2009 et 2010 - aux premières salves d'un projet mal compris et prématuré sur l'unification de la langue aché.

\section{Guaraché versus Achespagnol?}

L'espagnol est toujours mal et insuffisamment maîtrisé par les Aché du Nord qui s'expriment mieux en guarani paraguayen et utilisent, de nos jours, un 
mélange de guarani et d'aché, le guaraché, parlé dans six des sept communautés. Seuls, les Aché de Puerto Barra dominent pleinement l'espagnol, en revanche, ils ne comprennent que peu ou prou le guarani. Leur dialecte méridional, plus pur, à peine teinté ou saupoudré d'espagnol, n'est donc pas toujours intelligible par les Aché gatu du Nord. À maintes occasions, lors de réunions de travail, j’ai pu entendre ces derniers stigmatiser leurs difficultés à comprendre les Aché du Ñacunday (Puerto Barra). S'il ne faut pas forcer ce manque de fluidité linguistique entre les groupes méridionaux et septentrionaux, il ne faut pas non plus le minimiser. Ce trait rend parfois délicat, par exemple, le débat autour de concepts-clés des droits indigènes au sein de la FENAP, leur traduction et leur diffusion. De plus en plus, les jeunes aché qui dirigent les mouvements politiques doivent manier un savant sabir fait d'aché du Nord, de guarani et d'espagnol pour mieux communiquer.

En tout état de cause, les anciens de Canindeyú moquent toujours le jawu buchâ, l'«affreux parler» en usage à Puerto Barra. Pour eux, il ne s'agit pas seulement d'une différence dialectale, il s'agit d'une autre langue et mal parlée. Certains anciens du Nord vont jusqu'à affirmer que le mbyá-guarani sonne mieux et leur est plus intelligible que le dialecte incompréhensible et ridicule des Aché du Ñacunday. Une certaine mauvaise foi perce, à l'évidence, dans de tels propos énergiquement énoncés qui renvoient sans doute à un dénigrement ritualisé ou de convention que l'on peut supposer aussi coloré et réciproque du côté des vieux aché de la frange méridionale. Ils ne témoignent en aucun cas de la réalité des relations de solidarité dominantes qui se sont instaurées entre tous les Aché depuis le début des années 2000.

L'impact de ces différences dialectales dans l'imaginaire social demeure considérable et a été insuffisamment évalué par les missionnaires et les ethnolinguistes. Ces affaires de parlers ont eu assez de portée pour que les jeunes instituteurs et les parents d'élèves de Canindeyú se soient inquiétés de, aient questionné, puis décliné ou reporté sine die l'unification linguistique qu'on leur proposait. Celle-ci a été promue, à partir de 2005, par les églises évangéliques dans le cadre de leur croisade « Luz a los Aché » pour la traduction unique des évangiles (Edeb Piragi 2008, pp. 214-215), puis elle a été relayée, en 2008, par le projet ethnolinguistique de l'ADOP (Aché Documentation Project). En effet, s'il y a bien un point sur lequel les Aché refusent farouchement d'être assimilés aux autres groupes aché - en dépit de leur unité politique -, c'est celui de la langue. Aujourd'hui plus que jamais, les Aché du Nord tiennent jalousement à leurs singularités linguistiques et n'entendent pas gommer leurs différences d'intonation, de vocabulaire, leurs idiotismes, autant de marques distinctives qui constituent leur richesse, les identifient et les différencient des autres Aché gatu. L'uniformisation - dont ils n'ont pas eu l'initiative et dont ils n'ont toujours pas clairement saisi ni les tenants ni les aboutissants - attendra un peu et la traduction unique de la Bible aussi. 


\section{Les relations intercommunautaires}

En quête d'une identité aché commune et d'une unité ethnique transcendant leur hétérogénéité linguistique et quelques autres différences culturelles mineures auxquelles ils n'entendent pourtant pas renoncer (chants, peintures corporelles, objets utilitaires...), les communautés modernes ont développé et intensifié des formes de sociabilité qui réactualisent les visites que se faisaient traditionnellement les bandes au sein d'un même ensemble aché gatu. Les familles nucléaires continuent à voyager et à circuler librement entre les communautés, mais le moyen le plus important de se visiter et de fraterniser sont, aujourd'hui, les réunions annuelles pour l'anniversaire de la fondation des communautés. Toutes les colonies sont invitées à participer à cette grande liesse collective, qui peut réunir plusieurs centaines de personnes et durer un ou deux jours, placée sous le signe des jeux collectifs modernes et traditionnels. La joute traditionnelle à l'arc, aichu pira, qui oppose les meilleurs archers de chaque communauté, organisés en équipes, en est la manifestation la plus attendue et la plus spectaculaire aussi. Pour ce jeu d'adresse, les concurrents doivent atteindre une cible de la grosseur d'une tête de singe capucin, fichée à l'extrémité d'une perche attachée à la cime d'un arbre. Des joutes miniatures sont aussi organisées pour le groupe des femmes qui utilisent un arc plus petit et moins dur, ainsi qu'une cible disposée à moindre distance (Figure 16). Durant cette fête, où une à deux vaches peuvent être mises à mort pour alimenter les convives, des parties de football et de volley-ball mixtes sont organisées. Au sein d'un même département ou zone, il n'est pas rare, non plus, que les deux ou trois communautés les plus proches ${ }^{45}$ organisent un tournoi de football, sport auquel les Aché excellent et sont très attachés. Les Paraguayens locaux y sont conviés, ce qui permet de faire monter les enchères avec un prix en numéraire ou en nature (cochon, mouton, veau).

\section{Aché kreware : Aché contemporain}

Les Aché de 40 ans et plus, nés en forêt, gardent vivace le souvenir de cette vie sylvicole. Néanmoins, en 30 ans, une nouvelle génération d'Aché, nés et élevés dans les villages sédentaires, a acquis, au contact permanent avec la société dominante blanche et métisse, de nouveaux modes de vie. Ces jeunes aché, s'identifiant à des valeurs qui ne sont pas celles de leurs pères, cherchent à se rapprocher de la société métisse blanche. Ce processus s'est accéléré avec la présence des beru ymavegi, avec les voyages de plus en plus faciles et fréquents à Asunción ou dans les bourgades (compañia) environnantes. Au sein des conglomérats modernes où la réciprocité généralisée est devenue impossible, les valeurs les plus prisées traditionnellement du bon et généreux chasseur, du pourvoyeur de viandes respecté, n'ont presque plus cours. Les nouvelles générations aspirent à 


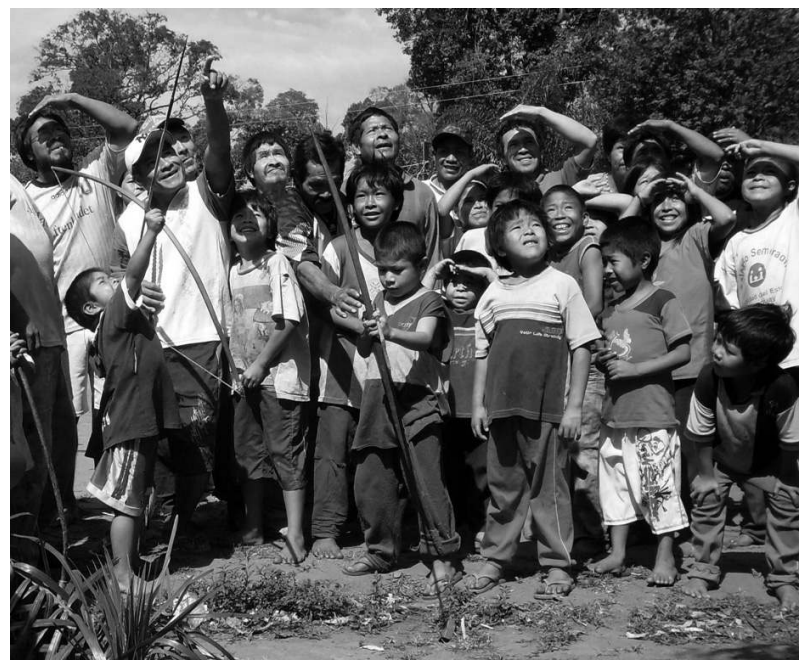

FIG. 16 - Pratique actuelle du tir à l'arc (Kuêtuvy 2008) (Cliché de l'auteur).

des études, des professions, un salaire... La vie des Aché contemporains s'articule entre le monde de la modernité et celui de plus en plus ténu, en voie d'estompement, de la tradition.

Pour ces Aché «contemporains » ou «modernes » (kreware), majoritairement bilingues, avec une dominante essentiellement guarani, le sentiment d'appartenir à une communauté nationale ne leur est pas tout à fait indifférent. Manger du riz et des pâtes, acquérir la carte d'identité nationale, soutenir l'équipe nationale de football, s'accompagner à la guitare pour chanter les airs de guarania ou polka paraguayenne, sont des moyens d'afficher leur citoyenneté paraguayenne. Pourtant, les Aché n'aspirent toujours pas à l'assimilation et se sentent différents du Paraguayen « de souche » - c'est-à-dire le métis guarani et espagnol qui parle guarani et qui est de confession catholique - qu'ils côtoient et avec qui ils sympathisent quotidiennement.

\section{Les Blancs}

Les Aché wa désignaient les Paraguayens sous le vocable de beru. Ce terme doit être pris dans son acception première, plus prosaïque et méprisante, de " mouche » ${ }^{46}$. Ils leur attibuaient ce terme, car les Paraguayens les harcelaient en forêt de la même façon, soulignent-ils, que le faisaient « des nuées de mouches rendues folles par leur odeur ». Il sera adopté par les Aché du Nord au moment de la sédentarisation et du contact avec les Aché wa. Les Aché du Nord utilisaient - et continuent encore à le faire - le terme non péjoratif de apâ, qui signifie 
«père » biologique et social. La pensée aché postule qu'il existait quelques relations de parenté mythologique entre les Blancs et les Aché dont l'origine commune apparaît dans le mythe des «planteurs de maïs ». Ces nomades pensaient aussi que les âmes tourmentées de certains morts étaient appelées à se réincarner en jaguar ou en Blancs malfaisants pour les vivants. Les Paraguayens, qui s'acharnaient sur les Aché et qui enlevaient les enfants, étaient parfois identifiés comme l'incarnation des mânes d'ancêtres ou de morts plus récents. Il me semble que l'on rend de façon impropre ou équivoque la signification $\mathrm{du}$ terme apâ si on ne s'en tient qu'à " pères » ou « aïeux », il faut chercher ailleurs l'explication de ce vocable appliqué aux Blancs. Apâ pourrait être, à mon sens, la traduction littérale en aché du terme mbyá $p a$ ' $i$, qui veut dire «médecin », « chamane », " prêtre », " père », et que les Guarani donnèrent aux premiers missionnaires. On peut penser, en effet, que les pères franciscains et les jésuites furent les premiers Blancs dont les lointains ancêtres des Aché entendirent parler et qu'ils apprirent à les désigner, grâce aux Mbyá, par ce terme qui aurait été appliqué depuis, par antonomase, à l'ensemble des Blancs.

Les Aché du Nord ont gardé le souvenir d'un autre terme tombé en désuétude qu'utilisaient leurs aïeux, pas si éloignés, pour désigner les Blancs : ropegi. La langue aché ignorant le 1, il est fort possible qu'il s'agisse d'une corruption du nom López (le Maréchal). On aurait là une preuve inattendue, mais supplémentaire, que des nouvelles des événements politiques du Paraguay, tel le conflit de la Triple Alliance (ou l'arrivée des missionnaires), parvenaient - sans doute amoindries et déformées, mais non moins sûrement - jusqu'aux habitants des forêts profondes de la région orientale.

Sous le terme générique apâ, qui subsume l'ensemble indifférencié de tous les non-indigènes, les Aché discriminent les Paraguayens qu'ils dénommaient : apâ proro « les Blancs qui tonnent», faisant allusion à leurs armes à feux et à leurs tueries. En contrepoint, les autres étrangers sont surtout les bujakrâfoagi « ceux qui vivent loin », « ceux du lointain ». Les Brésiliens, colonisant les territoires frontaliers du Paraguay, font partie de la vie quotidienne des Aché, lesquels sont de plus en plus obligés de traiter avec eux et de leur louer des terres. Les Aché du Nord ont fini par les dénommer plus spécifiquement boachugi, car ils sont élancés et souvent roux comme un daguet (Mazama americana).

\section{Le métissage et les alliances interethniques}

Le contact permanent avec la société nationale et le voisinage avec les Blancs ont conduit à la naissance d'une vingtaine d'enfants au sein des communautés. Ils sont le fruit d'unions sans lendemain, de relations éphémères nouées au cours d'une soirée avec des Paraguayens, parfois aussi avec des Brésiliens, ou encore de viols. Les unions stables ne sont pas rares non plus ${ }^{47}$, bien que le non-indigène doive se faire accepter par la communauté et s'engager à respecter quelques règles 
élémentaires de la sociabilité des Aché. Ces mariages mixtes contractés avec des Paraguayens (et un Brésilien) s'élèvent à dix-huit, selon mes derniers pointages, dans l'ensemble du groupe.

Aux dires des Aché, certaines congrégations évangéliques s'inquièteraient des mélanges génétiques de plus en plus fréquents avec les Guarani et seraient opposées au rapprochement marital et aux alliances politiques avec les autres autochtones de la région orientale, qu'elles tenteraient même de freiner ${ }^{48}$. Quoi qu'il en soit, les barrières traditionnelles de la méfiance et l'hostilité envers les Guarani s'amenuisent et sont même totalement tombées dans certains cas. Par exemple, en 2009, les Aché de Ypetimi ont participé à la structuration de la commission départementale de Caazapá avec les vingt-six autres communautés mbyá locales et un Aché wa en assume actuellement la présidence. En novembre 2009, quarante Aché de Ypetimi sont allés défendre - avec arc et flèches - les neuf familles mbyá de Tekoha Pyahu dont la réserve forestière était menacée par l'invasion des trafiquants de bois. Plus au nord, dans le département de Canindeyú, la petite communauté de Kuêtuwyve vit étroitement, depuis 2002, avec des familles Ava-Guarani qui participent activement à la consolidation de la communauté et à ses projets autogérés de développement durable. Par ailleurs, son organisation communautaire, LINAJE, siège et milite depuis 2003 au sein du conseil directeur de la Federación de asociaciones de comunidades indígenas guaraníes de la región oriental del Paraguay.

En dépit des pressions exercées sur eux, par des non-indigènes, pour vivre en autarcie ethnique et favoriser le moins possible les échanges interethniques, les Aché ont bien compris les intérêts qui les lient aux autres peuples autochtones et l'urgence de s'unir, de construire et d'approfondir de nouvelles alliances politiques pour défendre plus efficacement leurs droits. Ce rapprochement politique des Aché avec les Guarani se reflète aussi dans la nette augmentation des alliances matrimoniales passées, depuis quelques années, avec des Ava ou des Mbyá. Alors que, jusqu'en 1994 approximativement, il n'existait pratiquement pas de cas connus d'Aché mariés ou en concubinage avec des membres des autres groupes guarani (Susnik et Chase Sardi 1995, pp. 270-271 ; Hill et Hurtado 1996, pp. 85, 101), le phénomène du métissage s'est considérablement accentué depuis la fin des années 1990, où pas moins de vingt-quatre Aché (des hommes en majorité) ont été mariés ou vivent maritalement avec des Guarani (Mbyá ou Ava). Certes, les relations entre Aché et Guarani sont toujours difficiles et fragiles, il ne faut pas sous-estimer les résistances ou les frictions qui continuent - survivances du passé - à interférer dans l'issue de certains conflits fonciers entre les deux groupes. Par exemple, la réserve de biosphère de Mbaracayú, créée par le lobby écologiste privé (FMB, Guyra Paraguay), a suscité des jalousies entre les Aché, qui peuvent chasser et collecter avec leurs armes traditionnelles, et les Guarani, qui n'y ont aucun droit. Dans la zone-tampon de cette réserve écologique, le conflit sur le partage de la Finca 470 entre les Ava-Guarani et les Aché de 
Kuêtuvy est actuellement préoccupant (voir resolución 662/10 de la SEAM [www.seam.gov.py] ; Última Hora 23 et 24/06/10 ; ABC Color 28/06/10, 04/07/10).

Si l'on excepte ce cas de la Finca 470 - envenimé par les manipulations du lobby écologiste privé (ABC Color 28/06/10 ; Edeb Piragi 2008, pp. 201-202) - qui en est venu à miner sérieusement, depuis 2010 , la normalisation de ces relations interethniques, on peut affirmer que, globalement, l'ouverture et le rapprochement des Aché avec les peuples guarani priment et s'approfondissent. C'est un important indicateur de la vitalité et du discernement politiques des années 2000.

\section{LES ANNÉES 2000 ET LA CONSTRUCTION D'UN SUJET COLLECTIF : LA NATION ACHÉ}

En 1999, la population aché dépassait 1000 personnes, confinées au sein de cinq colonies représentant à peine 13000 ha de terres légalisées. Les ratés de la transition économique et le manque de solutions nouvelles, le pillage des dernières réserves et le trafic du bois, les tensions de vie au sein des conglomérats permanents de quarante à cinquante maisonnées, laissaient présager un avenir difficile. Au début de la décennie 2000, pourtant, l'exode de quarantecinq familles traditionalistes de Chupa Pou permet de fonder deux nouvelles communautés, Kuêtuvy (trente familles), en juillet 2000, puis Kuêtuwyve (dix familles) en février 2002, situées à $38 \mathrm{~km}$ de Chupa Pou et aux abords de la réserve de Mbaracayú. Leur création s'articule, cette fois, autour d'un projet d'autodétermination ethnique et non plus autour d'une mission religieuse comme dans les années 1970. En mars 2000, une première avant-garde de dix familles a définitivement abandonné Chupa Pou, en quête de nouvelles terres au cœur du territoire ancestral aché gatu. Les raisons profondes de cet exode sont la césure sociopolitique et idéologique avec les anciens captifs des Blancs, les beru ymavegi, et la mission catholique de Chupa Pou.

\section{Le schisme de Chupa Pou (1998-2000)}

L'analyse de ses causes n'a guère dépassé, chez les indigénistes du Paraguay ou autres experts, le niveau le plus apparent, à savoir celui du conflit généré par les désaccords internes sur la vente du bois, son rythme et la répartition des gains. En réalité, la crise de Chupa Pou a mis à nu les difficultés et la faillite - aggravées par les interférences négatives de la mission religieuse - d'une cohabitation permanente entre deux identités indigènes devenues antinomiques, celle des beru ymavegi, dont le mode de vie est hérité ou inspiré de leurs tuteurs et mentors paraguayens ${ }^{49}$, et celle des franges plus « traditionalistes » : les Aché nés en forêt ou dans les réserves, mais élevés auprès des anciens qui cherchent - entre tradition et modernité - une voie de développement viable et durable pour leur identité et qui tentent de maintenir un équilibre social et environnemental. 
Les efforts évidents de ces traditionalistes, à partir de mars 1998, pour structurer un vrai conseil politique représentatif des intérêts de la collectivité, plus conforme à la tradition aché que le «caciquisme » hérité des Blancs, s'étaient heurtés aux intrigues et aux ingérences des négociants de bois, très influents à Chupa Pou depuis 1993 et associés aux principaux partisans indigènes de la vente du bois. En août 1999, un peu plus de cinquante familles traditionalistes ont dénoncé officiellement la dilapidation illégale d'une partie de la réserve forestière de Chupa Pou. Face au laxisme des autorités judiciaires et de l'Église catholique, ainsi qu'à la menace d'un conflit fratricide (Edeb Piragi 2008, pp. 198-199), quarante-cinq familles décidèrent d'abandonner définitivement Chupa Pou.

Le schisme de Chupa Pou - entre beru ymavegi et Aché traditionalistes - est l'événement sociopolitique le plus saillant de l'histoire contemporaine aché. Il a incontestablement marqué un avant et un après pour les traditionalistes qui ont mieux pris conscience d'eux-mêmes, de leurs capacités et de la voie à suivre. Il a été la manifestation d'une volonté claire de s'émanciper des liens de dépendance forgés par la mission catholique et il a inauguré un processus - inédit - de distanciation des traditionalistes du Nord envers les beru ymavegi qui se montrent dominateurs (kachijabuâ) et peu respectueux de l'ethos aché.

Dès juin 2000, les principaux référents politiques des quarante familles en exode forment la toute première organisation du groupe, LINAJE (Liga Nativa por la Autonomía, Justicia y Ética), et revendiquent la légalisation de 4600 ha situés sur leur territoire traditionnel, pour y créer une réserve naturelle qu'ils veulent autogérer en conformité avec les savoirs ancestraux.

\section{LINAJE et les Aché de Kuêtuwyve}

La petite communauté de la zone-tampon de la réserve de biosphère de Mbaracayú s'est peu à peu imposée comme un espace de démonstration pratique et de réflexion collective des familles aché (et guarani), autour d'un développement indigène durable et autogéré, militant en faveur de petites unités de résidence, plus dynamiques, solidaires et variables, fonctionnant sur le modèle culturel d'une bande traditionnelle. La taille de Kuêtuwyve qui s'est stabilisée, avec le temps, à un noyau de cinq à six familles, explique fondamentalement le dynamisme et les initiatives de cette communauté.

Bien que LINAJE ait choisi de devenir progressivement une organisation communautaire, les réponses ou les solutions qu'elle a su apporter aux maux qui sclérosent les villages modernes (agglutination permanente, caciquisme, perte du rôle éducatif des anciens...), lui ont permis de gagner une écoute et un respect dépassant le rôle d'une simple organisation de base. Elle a ainsi obtenu le droit de siéger au conseil directeur de la Federación de asociaciones de comunidades indígenas guaraníes de la región oriental del Paraguay, regroupant huit autres 
associations d'Avá, Mbyá et Paî Tavyterâ, et a été l'un des promoteurs ${ }^{50}$ principaux de la création de la FENAP.

\section{Une Aché présidente de l'INDI (20 août-19 décembre 2008)}

Le 20 août 2008, le flambant neuf gouvernement de Lugo nomme, pour la première fois, depuis la création de l'institut national de l'Indigène (INDI) en 1981, une femme indigène à sa tête. Présentée comme une grande avancée pour la reconnaissance et l'expression des droits indigènes et féminins, cette nomination de Margarita Mbywângi, dirigeante de l' "Associación de Comunidades Aché » (ACA), est parée d'une symbolique très forte: kidnappée enfant, vendue et soumise aux pires sévices, cette femme, qui était retournée vivre chez les siens, avait pris une revanche formidable sur le destin. Mbywângi, candidate déçue au poste de sénatrice en avril 2008, était affiliée au parti politique catholique Tekojoja et appuyée par l'indigénisme d'obédience catholique dominé par la Conapi (Coordinación nacional de pastoral indígena), qui connurent, grâce à sa nomination, un court moment de victoire, tout juste quatre mois. Ces deux organisations ont, en effet, fait pression sur le président Lugo pour cette nomination. Elles l'ont obtenue en jouant la carte du quota politique, en dépit des réserves et de fortes réticences exprimées par certains secteurs indigénistes (y compris catholiques), des leaders et des organisations indigènes des deux régions du Paraguay. L'officialisation de sa candidature, puis sa nomination effective à la présidence de l'INDI, ne vont pas dans le sens des principes fondamentaux des droits indigènes, notamment en ce qui concerne la consultation des organisations autochtones du pays et des représentants légaux des vingt groupes ethniques. Ces derniers ont été, ainsi, privés d'un débat, dans leur communauté et au sein des associations indigènes, ayant pour but de décider qui seraient les deux candidats des régions occidentale et orientale, entre lesquels le Président de la république devait choisir.

La nomination de Mbywângi souffrait d'un autre manque de légitimité puisqu'elle n'avait jamais consulté les Aché sur son projet politique de sénatrice, ni sur son intention de se présenter à l'INDI. Les familles aché, les membres de l'ACA et de sa propre communauté de Kuêtuvy en ont été informés par... la radio, dans le premier cas, et lors d'une réunion du Front social et populaire ${ }^{51}$, dans le second. On peut considérer, en définitive, qu'elle n'a jamais été la candidate du peuple aché, mais bien celle du parti politique Tekojoja, même si tout a été mis en œuvre pour faire croire le contraire ${ }^{52}$.

L'attitude de Mbywângi peut s'expliquer. En effet sa tentative d'élection au sénat et sa nomination finale à l'INDI ont eu lieu à un moment où sa réputation était tombée au plus bas au sein du peuple aché et où l'ACA qu'elle personnifiait était discréditée depuis de nombreux mois. Tekojoja lui a donné une opportunité pour prendre sa revanche en entamant une carrière politique et pour tenter de 
sortir de l'état de disgrâce dans lequel elle était auprès des siens. À cet égard, constatons que son arrivée à l'INDI, le 20 août 2008, coïncide - presque date pour date - avec la création officielle de la FENAP, le 30 août 2008, qui a été consolidée et structurée, de juillet 2007 à août 2008, en réaction aux errements de l'ACA.

\section{Création de la Federacion Nativa Aché del Paraguay (FENAP) (30 août 2008)}

Le cycle des débats intercommunautaires en vue de créer la fédération aché a débuté à Kuêtuwyve, le 8 et 9 juillet 2007, à l'initiative de LINAJE. Ces réunions collectives se sont poursuivies à Puerto Barra, du $10 \mathrm{au} 12$ décembre 2007, puis du 15 au 17 mars 2008, à Ypetimi, du 31 mai au 01 juin 2008, pour culminer à Cerro Moroti, les 30 et 31 août 2008, où pas moins de trente quatre délégués des sept communautés ont paraphé les statuts collectifs de la FENAP. Ce document signale en exergue :

Des principes fondamentaux du droit consuétudinaire furent respectés de façon à ce que les préoccupations et interrogations des communautés aché soient profondément et collectivement débattues, que les décisions soient mûries et prises de façon consensuelle, conformément aux règles et à un rythme authentiquement aché, afin aussi que le cycle des réunions garantisse la construction progressive, mais sûre, d'une fédération légitime et autonome, capable de défendre les intérêts objectifs (présents et futurs) et l'unité du peuple aché. ${ }^{53}$

Il convient de souligner que les communautés ont, à chaque fois, réussi à s'organiser et à se mobiliser en toute indépendance économique, hors de tout agenda ou logistique des missionnaires. Précédent historique qui mérite aussi d'être souligné, le document officiel en espagnol fut traduit en aché et débattu collectivement, pendant un an, puis amélioré grâce aux apports et recommandations de chaque communauté avant d'être finalement accepté et signé, le 30 août 2008, par les délégations des sept colonies. Au cours de ces discussions intercommunautaires, les Aché ont accepté d'aborder un débat salutaire questionnant - pour la première fois - la cohésion et la cohérence sociopolitique de certaines communautés, parfois dominées et paralysées par des querelles intestines. En l'occurrence, les statuts de FENAP donnent la possibilité d'intégrer des « clans familiaux » (article 26) ou bien une coalition de clans qui en manifesterait la volonté ferme, dans le cas où un consensus serait impossible à réaliser, au sein d'une même communauté (Chupa Pou en l'occurrence), du fait des multiples pressions et manipulations - souvent exercées par les non-indigènes - qui sclérosent le fonctionnement démocratique des colonies sédentaires actuelles. 


\begin{tabular}{|l|l|l|l|}
\hline $\begin{array}{l}\text { ORGANISATIONS } \\
\text { ACHÉ }\end{array}$ & CRÉATION & TYPE ET CARACTÉRISTIQUES & ACTIONS MARQUANTES \\
\hline $\begin{array}{l}\text { LINAJE } \\
\text { (Liga nativa por } \\
\text { la autonomía, } \\
\text { justicia y ética) }\end{array}$ & juin 2000 & $\begin{array}{l}\text { - Communauté de } \\
\text { Kuêtuwyve (membres/ } \\
\text { sympathisants ailleurs } \\
\text { aussi) } \\
\text { - Intègre la Fédération } \\
\text { guarani (depuis 2003) } \\
\text { et soutient la FENAP }\end{array}$ & $\begin{array}{l}\text { - « Pronunciamiento » } \\
\text { Finca 470 (06/02/2006) } \\
\text { - Restitution des restes } \\
\text { aché du musée de la } \\
\text { Plata-Argentine } \\
\text { (mars 2007 à juin 2010) } \\
\text { - Ébauche des statuts } \\
\text { collectifs de la FENAP }\end{array}$ \\
\hline $\begin{array}{l}\text { ACA } \\
\text { (Asociación de } \\
\text { comunidades } \\
\text { aché) }\end{array}$ & août 2004 & $\begin{array}{l}\text { - Associative, rassemblant } \\
\text { des dirigeants officiels et } \\
\text { instituteurs de six } \\
\text { communautés } \\
\text { (Chupa Pou, Kuêtuvy, } \\
\text { Arroyo Bandera, Cerro } \\
\text { Morotí, Ypetimí, Puerto } \\
\text { Barra) }\end{array}$ & $\begin{array}{l}\text { mobilisation des Aché } \\
\text { pour réclamer à l'État } \\
\text { paraguayen, le titre } \\
\text { manquant des 2 158 ha } \\
\text { de Chupa Pou } \\
\text { - Occupation de la Plaza } \\
\text { Italia, Asunción, de mai à } \\
\text { juillet 2007 }\end{array}$ \\
\hline $\begin{array}{l}\text { FENAP } \\
\text { (Federación } \\
\text { nativa aché del } \\
\text { Paraguay) }\end{array}$ & août 2008 & $\begin{array}{l}\text { - Fédérative, rassemblant } \\
\text { des dirigeants officiels, } \\
\text { leaders naturels et } \\
\text { représentants d'anciens, de } \\
\text { femmes et adolescents des } \\
\text { sept communautés }\end{array}$ & $\begin{array}{l}\text { - Audience publique de la } \\
\text { « Comisión Verdad y } \\
\text { Justicia »le 17 juillet 2008 } \\
\text { - Accord de cogestion du } \\
\text { Parc national Caazapá } \\
\text { avec la SEAM le 20 janvier } \\
\text { 2010 }\end{array}$ \\
\hline
\end{tabular}

\section{Un sujet collectif}

Alors qu'elle était toujours en voie de structuration, la FENAP a passé son baptême du feu lors de l'audience publique du 17 juillet 2008, convoquée au Congrès national paraguayen, par la commission Verdad y Justicia (CVJ). Grâce à la représentativité et au dynamisme de ses principaux référents qui ont supervisé le processus au nom du groupe, les Aché ont affiché à Asunción une image d'unité, de solidarité et d'efficacité qui fut soulignée et applaudie par d'autres groupes: anciens du Nord et du Sud, plus jeunes et moins jeunes, femmes et hommes, Aché des colonies et Aché urbains, beru ymavegi, ont accepté de venir témoigner sur les atrocités perpétrés par la dictature contre la nation aché et les autres groupes du Paraguay (Melià 2008 ; Servín 2008 ; Edeb Piragi 2008).

Depuis la création officielle de la FENAP, en août 2008, les rapports de force au sein du groupe ont changé : fortes de leur unité politique, les communautés semblent vouloir apporter des réponses sociopolitiques nouvelles, plus cohérentes et durables aux crises. Nous allons tout de suite voir un exemple puisé au sein de l'actualité la plus récente. 


\section{Menace d'un second exode de Chupa Pou (février-mars 2010)?}

Dix ans ont passé depuis le schisme de Chupa Pou en 2000. Cette communauté a grossi démographiquement et compte pas moins de cent vingt familles, ce qui en fait actuellement la plus grande des sept communautés. Tout récemment, de février à mars 2010, un nouveau conflit a explosé et secoué très durement la colonie pendant plusieurs semaines consécutives. Le conflit a commencé à prendre une dimension inquiétante à tel point que soixante familles traditionalistes soudées autour d'un catéchiste évangélique respecté étaient prêtes - comme lors du premier schisme - à quitter Chupa Pou pour se rendre, à quelques kilomètres, au lieu-dit $Y$ Ruwa. Le conflit a éclaté parce que le verbita a décrété autoritairement le transfert d'une institutrice paraguayenne du collège agricole, pourtant appréciée par les parents d'élèves de Chupa Pou et que les traditionalistes se sont opposés à ce départ. Les ingrédients sont apparemment toujours les mêmes : une collectivité sûre de son bon droit, la prépotence du missionnaire qui s'entête, défendu par quelques beru ymavegi intraitables, parfois violents, et peu respectueux du consensus communautaire.

Aujourd'hui, les esprits se sont apaisés, la colère est retombée et le projet d'exode est abandonné. Le dénouement pacifique et rapide de ce conflit ne doit pourtant rien au hasard et contient quelques enseignements intéressants sur les changements qui sont intervenus au sein du groupe. En effet, les familles traditionalistes de Chupa Pou ont fait appel à la FENAP. De plus, le coordinateur général avait entrepris de réunir les principaux représentants des six autres communautés. La seule menace de cette médiation et la mobilisation du peuple aché ont suffi à forcer la congrégation du Verbe Divin, d'ordinaire incrédule et passive, à intervenir et à faire rentrer au plus vite le verbita de Chupa Pou dans les rangs.

\section{La restitution du territoire ancestral}

Profitant de l'actuel climat politique favorable aux peuples indigènes et du cadre juridico-politique des réparations promues et recommandées par la direction générale de la Verdad, Justicia y Reparación (créée le 23 février 2009, anciennement CVJ) et par la Defensoría del Pueblo - afin de restituer aux peuples originaires une partie des terres usurpées (tierras malhabidas) par la dictature militaire (1954-1989) - tout en garantissant la protection de la biodiversité, la FENAP a logiquement entrepris de défendre les droits collectifs du groupe sur l'ensemble du territoire ancestral commun ${ }^{54}$.

Conquête véritablement historique pour la nation aché, le 20 janvier 2010, la FENAP et la communauté des Aché de Ypetimi ont signé un accord de cogestion interinstitutionnelle du Parc national Caazapá avec la Secretaria del Medio 
Ambiente (SEAM), afin de garantir la préservation des 16000 ha de forêt atlantique de l'Alto Paraná, faisant partie antérieurement du territoire ancestral des Aché wa.

C'est incontestablement une victoire pour ce petit peuple de la forêt qui, pour parvenir à faire établir et parapher un tel document par l'État, a dû montrer du courage, de la détermination et une grande capacité organisationnelle. Il est entré à plusieurs reprises dans cette réserve publique avec arcs et flèches afin de paralyser le trafic du bois et de dénoncer méthodiquement (photos à l'appui) la complicité des gardes forestiers gouvernementaux avec les trafiquants d'essences précieuses et les scieries locales.

\section{CONCLUSION}

Par delà leurs différences linguistiques assumées, revendiquées même, et malgré un spectre sociologique changeant et compliqué par le retour, à l'âge adulte, de leurs enfants séquestrés en forêt, puis élevés sous tutelle non indigène, les quatre sous-groupes aché gatu ont su se rapprocher pour construire - sous la conduite des traditionalistes - leur unité politique et apprendre à parler d'une seule voix. Les efforts déployés, à partir de l'année 2000, pour dépasser les frontières artificielles des colonies sédentaires, pour rompre la compartimentation du groupe et son enfermement au sein des communautés contemporaines ont payé. Le peuple aché s'est fédéré en 2008 et est devenu un sujet collectif soucieux de son patrimoine naturel et culturel.

Certes, la FENAP récemment créée est encore fragile. Elle est le fruit d'un processus endogène, patiemment mûri, autodéterminé et tenace. Les franges traditionalistes des sept communautés ont déployé beaucoup d'efforts et de sacrifices, de discernement, pour mobiliser leurs forces vives, pour former des groupes alliés de travail ou encore pour consolider ceux déjà existants, sans provoquer de divisions ni de conflits au sein des communautés.

La nation aché a pu signer, au début de 2010, un accord historique encourageant et prometteur, destiné à protéger et cogérer la biodiversité des 16000 ha du Parc national de Caazapá. Les modalités exactes de cette cogestion, qu'il faut qualifier de pilote, restent à construire... Mais cela n'en demeure pas moins une victoire de la FENAP.

Travaillant simultanément sur tous les fronts de la consolidation identitaire, la LINAJE et la FENAP ont entrepris également d'œuvrer à la récupération de la mémoire collective afin de permettre au peuple aché de se réapproprier sa propre histoire méconnue des jeunes. À cet égard, les efforts entrepris en mars 2007 pour récupérer les restes osseux d'Aché sans sépulture, localisés dans les collections muséographiques d'Argentine (Arenas et Pinedo 2005 ; Duvojne Ortiz 2009 ; Última Hora 12/06/2010 ; ABC Color 12/06/2010 ; LINAJE 11-12/06/2010), ont 
été récompensés il y a peu. Le 10 juin 2010, le musée de La Plata a restitué au peuple aché la dépouille mortuaire de Damiana Kryygi $(† 1907)$, une adolescente kidnappée au XIX ${ }^{\mathrm{e}}$ siècle dans les forêts de Encarnación (département de Itapuá) et le crâne d'un jeune homme, tué à la machette dans les yerbales de Tavai (département de Caazapá). Leurs restes ont été rapatriés dans la communauté de Ypetimi, le 11 juin 2010, puis inhumés dans un lieu secret du Parc national de Caazapa, au terme d'une cérémonie rassemblant, pour la première fois depuis la sédentarisation forcée des années 1970, des anciens et des anciennes des sept communautés. *

* Manuscrit reçu en mai 2010, accepté pour publication en juin 2011.

\section{Notes}

1. Par exemple, les Aché du Nord distinguent entre eux : les Aché gatu ou « Aché de référence » et les autres Aché, tels ceux de l'Yvytyrusu qui sont des Aché purâ, Aché " distincts », " pas authentiques » ou Aché doroiâmbyty, «Aché que l'on ne rencontrait jamais » ou encore les Ache irô-iâ, "Aché non-compagnons », enfin les Aché wa, «ceux qui sont des mangeurs de Aché ».

2. Depuis l'arrivée des jésuites au Paraguay en 1610, les archives de l'ordre font état de sauvages qui vagabondent sans lieu fixe et ont « des visages semblables aux singes », de Guayaki capturés par les Guarani à la solde des jésuites : aux environs de 1627, est mentionnée la capture d'une quinzaine d'adultes et enfants confiés à la réduction de Acaray dans la province de Guairá (Jaime Cortesâo 1951, cité dans Renfeld 2000, p. 164); au XVIII ${ }^{\mathrm{e}}$ siècle, une bande de trente Guayaki est convertie dans la mission de Jésus dirigée par le père Manuel Arnal (Hervás y Panduro 1800-1805, p. 195).

3. On peut ajouter aux 1800 hectares de Cerro Moroti, les 1200 hectares de Chupa Pou, créés en 1978 par les missionnaires catholiques pour accueillir les familles qui fuyaient Cerro Moroti et celles, rescapées, qui s'entassaient à Arroyo Manduvi depuis 1975 (Smith 1975; Smith et Melià 1978).

4. Les Aché du Sud, ceux du río Ñacunday, aujourd'hui sédentarisés à Puerto Barra, connaissent parfaitement ces pièces maîtresses de l'oralité aché («l'homicide à la jambe pointue », " tapir le cogneur », ita jiwagi ou « l'oiseau du piton rocheux ») de diffusion pan-amazonienne. C'est donc bien que le récitatif nous renvoie à un héritage culturel commun des Aché, remontant, pour le moins, à une époque lointaine où tous les sous-groupes aché gardaient encore un contact entre eux et où la nation aché n'avait pas encore éclaté en unités aché gatu géopolitiquement séparées, figées sur des frontières rigides.

5. Voir Vellard (1935, pp. 191-194), Cadogan (1968b ; 1992), Edeb Piragi et Kanjegi (s.d.a).

6. En un principio, los Guayaki y los Mbyá vivían juntos bajo el gobierno de Pa'i Rete Kuaray [el Shaman del Cuerpo como el Sol, o héroe cultural máximo mbyá-guaraní]. Un día los Guayaki aparecieron en la danza ritual completamente desnudos y Pa'i, enfurecido, los apostrofó con la sentencia: Guayakí ¡ javá moreká! dispersándolos por la selva. Es por este motivo que viven errantes y salvajes hasta el presente (Cadogan 1959, p. 84 ; 1968a, p. 133. Traduction en français de l'auteur dans le texte).

7. Un arbre tendre de la famille des caricacées : Jacaratia spinosa. Les Aché en consomment le grand fruit orangé rôti à la braise, car le liquide laiteux contenu dans sa pulpe crue brûle les lèvres. De plus, c'est un arbre important pour les élevages de larves, qui donnait traditionnellement lieu à un abattage extensif, au point que sa floraison constitue un repère fondamental du calendrier aché. Le cœur aqueux de cet arbre était, par ailleurs, un précieux auxiliaire de l'homme dans les zones dénuées de cours d'eau.

8. C'est le même charançon (Rhyncophorus palmarum) qui pond ses œufs dans le Jacaratia spinosa et le palmier pindo (Syagrus spp.), mais la technique de préparation des élevages de larves diffère : dans le cas du palmier, c'est le stipe entier - préalablement abattu - qui sera colonisé, tandis que, dans le cas 
du jacaratia, c'est la souche de l'arbre encore sur pied et coupé à une hauteur minimale de $1,5 \mathrm{~m}$ (Figure 9) qui est colonisé par le haut. Au fur et à mesure que les larves croissent, elles s'alimentent de la pulpe molle et aqueuse du tronc jusqu'à atteindre la base de la souche et en sortir, lorsqu'elles parviennent à maturité.

9. Pour le texte complet du mythe en espagnol, voir Edeb Piragi (2001, pp. 230-233).

10. Compte tenu des correspondances linguistiques entre le guarani et l'aché, il est tentant de penser que le buara des Aché serait une antonomase dérivant du terme guara par lequel les Guarani désignaient le territoire ethnique (sur cette notion de guara, voir Susnik et Chase Sardi 1995, pp. 35-41 en particulier ; Bartolomé 2003, pp. 221, 224 et sq.).

11. Dans la langue mbyá-guarani, mbyá signifie « personne adulte », "gens » (Cadogan 1992, p. 118), « foule » (" muita gente num só lugar », in Dooley 1998, p. ixxii).

12. En aché, l'élision du y devant la voyelle a, qui peut ou non se redoubler, est un phénomène linguistique fréquent : $(\mathrm{M})$ byá $=(\mathrm{M}) \mathrm{ba} /(\mathrm{M}) \mathrm{baa}$ (gens) $;$ wya $=$ waa (odeur pénétrante désagréable) $;$ pya $=$ paa $($ foie $)$, etc.

13. Pour le texte du mythe, voir Edeb Piragi (2001, pp. 233-236).

14. À l'exception de trois petites bandes qui vont s'installer en bordure des zones boisées pour continuer à battre la forêt quotidiennement (Edeb Piragi 2008, pp. 188-190). À la fin des années 1990, l'une d'elles, sise à Mboi Jagua (dénommée Arroyo Bandera à partir de 1994), est devenue une communauté de quasi trente familles, tandis que les deux autres bandes de Yvy Pytâ et Y Ruwa se sont fondues au sein de Chupa Pou.

15. Les excursions en forêt ne sont plus lancées qu'à intervalle moyen de deux à trois semaines, voire plus (Hill et al. 1984 ; Edeb Piragi 1992, p. 140). Elles n'excèdent pas quinze jours et s'apparentent presque exclusivement à des expéditions de chasse : en 1982, elles ont pris l'allure de traques au pécari (Edeb Piragi 1992, p. 141) puisque la farine du pindo n'était pas exploitée et beaucoup de fruits étaient ignorés. Ainsi que j'ai pu l'observer, à partir de 1986, les tabous alimentaires n'avaient presque plus cours et les règles de traitement du gibier n'étaient déjà plus respectées (Edeb Piragi $1992 ; 1994 ; 2008)$.

16. Voir supra la note 14.

17. Selon Clastres $(1967 ; 1972)$ et les anthropobiologistes nord-américains, Hill et Hurtado $(1996$; 1999), les Aché auraient été avant tout tributaires de la chasse, ce d'autant que le gibier assurait $78 \%$ des calories totales de l'alimentation des familles engagées dans les excursions de cinq à quinze jours, étudiées par eux entre 1980 et 1982 (Hill et Hawkes 1983 ; Hill et al. 1984). Nous avons montré ailleurs que ce point de vue ne s'étayait sur aucune mesure chiffrée chez Clastres dans les années 1960 et se fondait sur des enquêtes statistiques biaisées par les profonds changements économiques des bandes observées par Hill et son équipe, à partir des années 1980 (Edeb Piragi 1992) : la méconnaissance par ces chercheurs du champ rituel et symbolique de ce peuple nomade, ainsi que leur vision simpliste du champ culturel, spirituel et sociologique qu'ils réduisent à des épiphénomènes des nécessités physiologiques et des contraintes écologiques les conduisent à minimiser la profondeur des transformations politico-religieuses provoquées par la sédentarisation et leur véritable impact économique sur les activités sylvicoles modernes (Edeb Piragi 1992) : ni les rendements de chasse, ni le modèle cynégétique observable de 1980 à 1982 ne sauraient être ainsi utilisés, sans précaution, pour rendre compte du mode de ponction traditionnel.

18. Ce goût, véritablement immodéré, des Aché pour la graisse animale les portait à ne jamais omettre de récupérer le gras d'une carcasse déjà au bord de la putréfaction, ni de prélever, à l'occasion, le tissu graisseux d'un renard à crinière rousse (Pseudalopex gymnocercus, pepe jykâ en aché), pourtant l'un des rares animaux réputés, par eux, comme étant peu comestible. À l'inverse, ces Indiens savaient se retenir de manger un gibier trop maigre, et des chasseurs n'hésitaient pas, notamment si le chemin du retour au camp était encore long, à se défaire d'une prise famélique jugée encombrante. À propos d'une « lipophilie » similaire chez les Matis amazoniens, voir Erikson (1996, p. 197).

19. Ces festivités sont apparues depuis la sédentarisation grâce à l'existence, dans les réserves modernes, d'un registre d'état civil tenu par les missionnaires et permettant de consigner les dates de naissance. 
20. Cet engouement alimentaire pour la viande d'élevage contraste avec les réticences généralement manifestées par les Amérindiens pour la consommation de viande domestique [pour des références bibliographiques sur ce thème et sur une autre exception à cette règle amérindienne que constituent les Chacobo amazoniens, voir Erikson (1998, pp. 370-371 et note 5)]. Afin de l'expliquer, rappelons que les Aché connaissaient et fléchaient le bétail d'introduction ancienne des Blancs et qu'ils prisaient, tout particulièrement, la viande de cheval et d'âne qu'ils considèraient plus saine que celle de vache ou de bœuf. Depuis la fin des années 1990, il est devenu difficile, voire rare, d'obtenir de la viande chevaline auprès des Paraguayens qui n'en consomment pas eux-mêmes - sauf sous forme de salamis -, mais qu'ils ont artificiellement surenchéri du fait de l'addiction des communautés aché pour ce mets.

21. En 1980, l'ensemble des cinquante familles de Chupa Pou cultivait à peine 5 ha, surface qui passera à 25 ha en 1982, puis à 79 ha en $1989: 13$ des 30 lopins (entre 0,5 et 6,25 ha) sont cultivés collectivement par des groupes de deux à six travailleurs (Renshaw et Reed 1990, p. 32).

22. Parmi les groupes de la zone, les employeurs paraguayens et brésiliens préfèrent de très loin embaucher les Aché qui sont fort appréciés pour leur volontarisme et leur résistance à l'effort, ainsi que leur contact plus facile et moins conflictuel, selon eux, que les travailleurs guarani.

23. Sauf peut-être un peu de la part d'Alejandro Pytel, un religieux différent et, donc, rapidement éloigné des Aché en 1983 pour ses divergences avec sa congrégation, la société du Verbe Divin, de la part aussi de la Misión Alemana de los Nativos del Paraguay qui a mis en place, à la fin des années 1980, des ateliers de formation sur les systèmes agro-forestiers et agro-écologiques. Il me semble, néanmoins, que transmettre de telles connaissances sans donner les moyens d'une mise en application directe et rapide dans la communauté ou pour n'être qu'un prétexte à l'évangélisation ne peut qu'aboutir à un échec. À partir de 1994, j'ai commencé à travailler avec quelques comités paysans et leurs techniciens agroforestiers pour sensibiliser les Aché d'Arroyo Bandera, puis de Chupa Pou, à l'importance des plantations d'essences natives, l'enrichissement de forêt secondaire, l'agriculture de sous-bois, l'horticulture organique, le semis direct, etc.

24. Dans le chapitre consacré à la communauté moderne des Aché, par exemple, Renshaw et Reed (1990, p. 26) soutiennent que « les Aché maintiennent encore leur identité communale et les réserves actuelles coïncident de certaine manière avec les populations traditionnelles » (italiques et traduction en français de l'auteur. "los Aché aún mantienen su identidad comunal y los asentamientos actuales hasta cierto punto corresponden a las poblaciones tradicionales »). Cette donnée a été reproduite, entre beaucoup d'autres synthèses ou écrits sur les Aché, dans le rapport anthropo-juridique préparé par le département des Droits ethniques du Paraguay (Ministerio público del Paraguay 1999, p. 93).

25. En forêt, l'unité sociopolitique intégrait l'ensemble de toutes les bandes locales qui se reconnaissaient parentes ou amies et se définissaient ache gatu. Chaque bande locale formait une unité socio-économique de sept à quinze familles apparentées ou unies par des liens d'affinité, possèdant un ekoãndy, " lieu coutumier de vie », qui délimitait approximativement une zone de nomadisme privilégiée au sein du territoire commun. Le partage des produits d'une chasse ou d'une cueillette abondante et les visites régulières aux unités résidentielles les plus éloignées étaient la règle et la condition sine qua non pour la cohésion tribale ache gatu.

26. Hill et Hurtado (1996; voir aussi Münzel 2008, p. 16) sont parvenus à dresser une liste de 544 Aché du Nord encore vivants en 1970. Faut-il en conclure, comme eux, que la taille de ce groupe ne devait pas excéder ce chiffre ? Nous ne le pensons pas pour avoir pu constater, d'une part, des variations sensibles entre leurs chiffres et ceux, pourtant incomplets, que j’ai rassemblés sur le nombre des victimes décédées en forêt au cours de circonstances précises (comme une attaque des Blancs ou une morsure de serpent, l'attaque d'un jaguar ou encore la foudre...) et, d'autre part, des causes de décès - d'avant et durant le premier contact de 1970 - qui ne sont pas référencées par ces auteurs (données personnelles encore inédites ; voir aussi Edeb Piragi 2008, p. 186 et la note 13, p. 216). Ces manques comme ces différences statistiques sont déjà un indicateur permettant de conclure à la non-exhaustivité de leur échantillon. À cet égard, au long de vingt années d'enquêtes ethnographiques, j'ai pu relever les noms de personnes sans descendance, ni proches parents - consanguins ou non - vivants (n'oublions pas que près ou plus de $50 \%$ de la population du Nord fut décimée après 1970). L'existence de ces personnes est 
très difficile à détecter si l'on ne s'adonne pas à un relevé systématique des données généalogiques, en tenant bien compte de la parenté symbolique (jary, bykuaregi, paternité multiple...) et des alliances matrimoniales, en croisant également ces données avec les histoires de vie et tous les individus qui y sont mentionnés. Une autre difficulté provient du registre limité des noms aché portés, presque tous, par les personnes de sexe masculin et féminin indistinctement, qui impose un protocole assez lourd de redécoupages pour identifier précisément le détenteur d'un nom donné (Tatugi, Chachugi, Bywângi...), lequel est généralement partagé, si on remonte seulement jusqu'au début du $\mathrm{xx}^{\mathrm{e}}$ siècle, par au moins quelques centaines d'Aché du Nord des deux sexes et de n'importe quel âge.

27. Selon Luis Duarte en particulier, cité in Escobar (1988, p. 205).

28. En 1989, les cinq colonies regroupaient 498 Aché du Nord (Hill et Hurtado 1996, p. 56) : 285 vivaient à Chupa Pou, 150 à Cerro Moroti, 34 à Arroyo Bandera, 28 à Ypetimi et 1 à Puerto Barra.

29. À la fin des années 1980, l'État paraguayen n'avait toujours pas cherché à indemniser les Aché pour le vol de leurs territoires. En 1988, les cinq colonies peuplées par quelque 206 familles aché, avoisinant 700 personnes, représentaient à peine 5200 ha de terres légalisées. 6000 ha supplémentaires furent concédés par le gouvernement paraguayen en 1993, en forme de compensation pour la création de la réserve de Mbaracayú et pour renoncer, surtout, à faire valoir des prétentions ethniques légitimes sur une gestion souveraine de ces 60000 ha de forêts subtropicales encore miraculeusement épargnées au cœur du département de Canindeyú.

30. Sur les maux et dysfonctionnements de l'institution du « caciquisme », voir Edeb Piragi (2008, pp. 193-194). Traditionnellement, les Aché n'avaient pas de leader général, ni de chef politique, même s'ils acceptaient d'être dirigés, dans des situations déterminées (chasse collective, défense du territoire, lutte rituelle...), par des chasseurs prestigieux, habiles et expérimentés. Les bandes se gouvernaient, plus fondamentalement, par le consensus et l'adhésion librement consentie des familles, les décisions se prenant collectivement et chacun pouvant exprimer son opinion. Tout change lorsque, sous prétexte de désigner des porte-parole ou des représentants officiels pour dialoguer avec la société nationale, les Blancs instaurent le « caciquisme », forme de pouvoir individualisée et manipulable qu'ils concentrent entre les mains de jeunes aché (kybuchuve) inexpérimentés et malléables. Le " caciquisme » a clairement visé à contrecarrer le système du leadership traditionnel monopolisé, aux yeux des Blancs, par les hommes mûrs (ymagi).

31. Loi 904/81 « Estatutos de las comunidades indígenas ».

32. C'est-à-dire les représentants légaux et les leaders naturels des 3 plus grandes concentrations de Aché du Nord de l'époque : Chupa Pou, Arroyo Bandera et Cerro Moroti, ainsi que les mandataires des familles du Nord vivant à Ypetimí. Par ailleurs, toute dévolution et titularisation d'une terre traditionnelle affectant vitalement l'existence, le bien-être et le développement intégral -présent et futur - du groupe entier, ce sont bien tous les représentants légaux du peuple Aché qui auraient dû être consultés et conviés à la table des négociations pour débattre de cette question historique avec l'État paraguayen, la Banque Mondiale (propriétaire des 60000 has de forêt) et le lobby « écologiste » multinational.

33. Quelques années plus tard, à partir de 2002, le même lobby vert s'appliquera, avec des méthodes similaires, à récupérer et dénaturer les revendications ethniques des Aché du Nord installés à Takua Poty, puis à Kuêtuvy, en désarticulant leurs prétentions sur les 4600 ha de la finca 470 de toute velléité d'auto-détermination et de gestion souveraine de la dernière biodiversité subtropicale (Edeb Piragi 2008, pp. 200-202, 219 note 44), au profit d'une gestion, verticale et paternaliste, contrôlée et dirigée par les prétendus écologistes.

34. À l'exception notable de la communauté de Kuêtuwyve, née de la sous-division politique de Kuetuvy en décembre 2001, qui a choisi de fonctionner comme une bande traditionnelle (Edeb Piragi 2008, pp. 202-203).

35. Un bon exemple nous est fourni par Renshaw et Reed (1990, p. 27) qui participent à une réunion sur la répartition des gains de la vente du bois à Chupa Pou et qui en concluent que «la majorité ne peut pas imposer ses idées ; le concept de vote, par exemple, n'existe pas et, dans le cas où il est impossible de convaincre l'autre partie, les participants doivent parvenir à quelque accord mutuel. Dans certains cas, les réunions se terminent par des décisions que la majorité sait par avance erronées. 
[...] Finalement, il fut décidé d'affecter une partie de l'argent au magasin [de la colonie] et le reste fut réparti sans générer aucun bénéfice pour la communauté » (traduction en français de l'auteur. "la mayoría no puede imponer sus ideas ; no hay ningún concepto de votación, por ejemplo, y, si no pueden convencer a los otros, los participantes tienen que lograr algún acuerdo mutuo. En algunos casos las reuniones terminan en decisiones que la mayorí ya de antemano reconoce como equivocadas. [...] Alfinal se llegó a un acuerdo por el cual parte del dinero fue a abastecer el almacén y el resto fue repartido, sin lograr ningún beneficio para la comunidad»).

36. En août 2008, pour la première fois dans l'histoire moderne des Aché sédentarisés, le texte des statuts de la fédération native aché du Paraguay (FENAP) dans son article 6 alinéa g recommande de « veiller à ce que des personnes, non dûment ou suffisamment légitimées par la FENAP et par conséquent l'ensemble du groupe, n'aillent revendiquer leur représentativité, ni parler au nom du peuple ou de la nation aché » (" velar para que individuos no debida y suficientemente legitimados por la FENAP y, por ende, el conjunto de la etnia, no invoquen la representación ni hablen en nombre del pueblo o la nación aché». Traduction en français de l'auteur).

37. Convergents et nombreux sont les témoignages indiens qui démontrent que la réincorporation de ces captifs dans leurs familles et groupe d'origine ne fut pas un processus aussi aisé, naturel ou serein, que pourrait le laisser croire leur rapide ascension politique au sein des communautés. Servín (2008) livre, sur ce point, quelques témoignages éclairants (conformes à ceux que j'ai eu maintes fois l'occasion d'écouter depuis 1986) enregistrés, entre 2007 et 2008, dans le cadre de la Comisión verdad y justicia (CVJ), auprès de beru ymavegi des deux sexes : «Parvenu à ce point, Joaquin [leader en second de Arroyo Bandera et ancien cacique de Chupa Pou] dut interrompre son récit à cause des sanglots et la profonde tristesse [qui] envahissait son visage. S'étant ressaisi, il raconta qu'en de nombreuses occasions $i l$ se sentait rejeté par les indigènes pour le fait de penser différemment ; il affirma qu'il aime son peuple, se sent préoccupé pour ses gens mais que la cohabitation lui coûte. Pour tout cela, il déplore ce qui est arrivé aux Aché » (p. 171. Italiques de l'auteur). «Au début il lui fut [Margarita, présidente de l'ACA] très difficile de vivre dans la communauté parce que sa population la rejetait et lui disait : "par votre faute à vous les Blancs, nous avons perdu nos familles!' Elle tentait de leur expliquer seulement qu'elle avait été enlevée par les Paraguayens et avait vécu loin de sa famille contre sa volonté. Elle a beaucoup souffert de ne pas connaître la langue et de ne pas être accoutumée au mode de vie des Aché [...]. Cela se passait durant la décennie de 1980, quand la région de Curuguaty était encore pure forêt et la colonie souffrait du manque d'aliments (p. 175. Italique et traduction en français de l'auteur. « $A l$ llegar a este punto, Joaquín [vice-leader d'Arroyo Bandera et ancien cacique de Chupa Pou] no pudo seguir el relato por las lágrimas, y una honda tristeza cubrió su rostro ; luego de reponerse, contó que en varias situaciones se siente rechazado por los indígenas, por pensar diferente ; afirmó que ama a su pueblo, se preocupa por su gente, pero le cuesta la convivencia. Por todo ello, lamenta lo sucedido con los Aché », p. 171. « Al principio le [Margarita, présidente de l'ACA] fue muy dificil vivir en la comunidad, porque su gente la rechazaba y decia : "Por culpa de ustedes, los blancos, perdimos a nuestras familias". Ella trataba de explicarles que nada más fue cazada por los paraguayos y que vivió lejos de su familia fuera de su voluntad. Sufrió mucho pues no sabía el idioma, y no se acostumbraba a la forma de vida de los Aché [...]. Eso fue en la década de los 80, la zona de Curuguaty era aun todo monte, en la comunidad no habia suficiente alimentos », p. 175).

38. Durant l'existence sylvicole, les rapts opérés par l'homme blanc provoquaient des coupes sombres dans la population infantile et représentaient $57 \%$ du total des causes de disparition des enfants de 4 à 14 ans (46 enfants) des bandes nomades du Nord et $16 \%$ (20) pour les nourrissons de quelques mois à 3 ans (Hill et Hurtado 1996) : à ce chiffre de 66 victimes de rapt (ibid., pp. 171-172), il faut ajouter les 42 enfants qui furent enlevés ou capturés par les Paraguayens durant la période du contact (1971-1977), ce qui nous donne un total de 108 jeunes victimes, recensées par ces auteurs. Selon mes propres statistiques, aux 36 Aché réapparus dans les communautés ou localisés, il faut encore ajouter 78 noms dont les anciens ont conservé le souvenir très vif, ce qui donne un total légèrement supérieure de 114 enfants kidnappés par les Paraguayens entre 1960 et 1977 pour les seuls Aché septentrionaux. Ces chiffres ne remontant pas à une période supérieure à 1960, ils ne sont pas complets 
et confirment, une fois encore, mes doutes sur l'exhaustivité des données démographiques de Hill et Hurtado (voir supra note 26).

39. Voir la réponse du conseil directeur de LINAJE reproduite dans la page d'opinion de Última Hora du 22/03/2006 et sur le noticiero de l'organisation (www.linaje.org) sous le titre : « A la mujer aché "invizibilizada" " 16/03/2006.

40. C'est ainsi qu'elle continue de s'auto-proclamer sur un site officiel aché jau mis en ligne sans l'agrément préalable des autorités politiques de Kuêtuvy d'alors, ni de la plupart des anciens qui y sont montrés et qui le signifieront en diverses occasions - mais en vain - à l'intéressée et aux promoteurs du site.

41. Pour les Aché, la femme enceinte possède des vertus curatives. La présence de l'enfant en gestation lui confère un état de « froideur » qui soulage les douleurs grâce à l'apposition de ses mains sur les parties endolories ou blessées. Les Aché pratiquaient aussi naguère des rites d'assistance et d'accompagnement collectif des malades afin de permettre au souffle vital ( $k r e i)$ de réincorporer le corps de la personne inconsciente ou en état comateux.

42. Dans les deux cas, la négligence des missionnaires a provoqué le décès d'un membre adulte apprécié du groupe.

43. Éminent connaisseur du aché, León Cadogan (1968b, p. 153) rapproche pourtant, à tort, le purâ aché du porâ guarani, le traduisant par hermoso, verdadero. Purâ signifie précisément le contraire, « étrange », " pas authentique ».

44. À la suite, très précisément, d'une lutte funéraire (tômumbu) à massues, qui a été endeuillée par la mort d'un participant (Edeb Piragi 2005, pp. 215-216, 224 note 5).

45. En juin 2010, les deux plus grandes colonies aché actuelles de Ypetimí et de Chupa Pou ont organisé - malgré l'éloignement géographique - plusieurs rencontres de football au cours desquelles des sommes d'argent assez importantes étaient engagées.

46. Pour des raisons qui m'échappent toujours, León Cadogan et Pierre Clastres pensaient que ce terme devait bien comporter quelque connotation positive, le premier faisant l'hypothèse que ce terme avait une relation probable avec le terme aché $t u$ qui signifie « père » (1968b, p. 17) et Clastres affirmant que beru « signifie les âmes des Ancêtres » (ibid., avant-propos).

47. Notons que, contrairement à ce que j'écrivais en 2008 (p. 207), ces unions avec les Blancs sont légèrement inférieures aux alliances matrimoniales avec les Guarani.

48. Je crois que ces réticences tiennent principalement à la crainte de voir l'insoumission religieuse et politique des Guarani - et des Mbyá, tout particulièrement, qui continuent à rejeter farouchement l'entrée des missionnaires chrétiens dans leurs communautés - déteindre sur les Aché, radicalisant leurs comportements, systématisant des volte-face qui ont joué plus d'un mauvais tour à des congrégations religieuses pourtant implantées dans les colonies aché depuis des lustres.

49. Les beru ymavegi ont fini par introduire et imposer à Chupa Pou un modèle des conduites héritées des Blancs, culturellement inusitées, inconcevables avec les valeurs traditionnelles, qui bousculent les principes du dialogue et du consensus collectif inhérent à la démocratie aché : ce sont, par exemple, les intimidations physiques et menaces de morts contre des non-sympathisants, la violation caractérisée du consensus majoritaire... (Edeb Piragi 2008, pp. 198-199, note 41).

50. LINAJE rédigea, notamment, le premier jet de la convention collective qui fut débattue durant plus d'une année au sein des sept communautés pour aboutir au texte final des statuts sociaux de la FENAP.

51. Le 14 juin 2008, le « front social et populaire », Frente social y popular (FSP), une coalition de mouvements sociaux et syndicaux toujours « en formación » [sic], selon ce qui est écrit dans sa lettre d'invitation, a convoqué les organisations autochtones du pays « a un encuentro de lideres y representantes indigenas para presentar propuestas de politicas públicas para los pueblos indigenas ». L'invitation était signée par José Parra (FSP) et Margarita Mbywângi (membre de la table indigène du FSP). De nombreux indigènes des deux régions du Paraguay étaient présents, car le bruit avait couru que le président Lugo serait présent. Il n'est pas venu. La réunion n'avait en réalité pas pour but de présenter des propositions de politiques publiques pour les peuples indigènes, mais de désigner les candidats 
indigènes éventuels pour la présidence de l'INDI. Les leaders pris de court se sont retrouvés dans l'impossibilité de consulter les membres de leur communauté ou leur organisation car «il faut faire vite », leur avait-on dit. Quelques tentatives isolées de boycott ont été menées, mais en vain. Margarita Mbywângi, qui animait les débats, fut l'une des candidates retenues.

52. Quelques mois plus tard, au moment de la destituer, Lugo fera valoir à sa manière ce qu'il croyait savoir de Margarita Mbywângi et accusera finalement plus le peuple qui l'avait prétendument élue que la candidate elle-même. Une injustice de plus pour ce peuple qui n'a même pas reçu de bénéfices de cette présidence : «El presidente de la república, Fernando Lugo, justificó la destitución de Margarita Mbywangi del Instituto Nacional del Indigena alegando que la misma favoreció sectariamente a la etnia a la cual pertenece, los aché » (La Nación 24/12/2008).

53. Se respetaron principios consuetudinarios fundamentales para que las preocupaciones e interrogantes de las comunidades aché sean colectiva y profundamente debatidas, las decisiones sean maduradas y consensuadas conforme a pautas y un ritmo genuinamente aché ; para que el ciclo de reuniones afiance la construcción paulatina pero segura de una federación legítima y autónoma, capaz de obrar en defensa de los intereses objetivos (presentes y futuros) y de la unidad del pueblo aché (traduction en français de l'auteur dans le texte).

54. Aujourd'hui le peuple aché détient potentiellement 18969 ha - dont seulement 14369 ha sont légalement assurées - pour une population de 1650 personnes environ, qui dépassera bientôt les 2000 individus. Cette démographie galopante est préoccupante si l'on prend en compte le manque de terres et de perspectives économiques claires, comme l'usure rapide des sols aggravée par une mécanisation grandissante.

\section{RÉFÉRENCES CITÉES}

Arenas Patricia et Jorge PINEdo

2005 «Damiana vuelve a los suyos », Revista Radar, 21 de noviembre [http : //www.pagina12.com.ar/diario/suplementos/radar/9-2639-2005-11-21.html ; htttp ://www.arteuna.com/convocatoria_2005/Textos/pinedo.htm, consultés le $31 / 01 / 2006]$.

BALDUS Herbert

1972 «Die Guayaki im Paraguay (nach Angaben F.C. Mayntzhusen und eigenen Beobachtungen) », Anthropos, 67 (3-4), pp. 465-529.

BARTOLOMÉ Miguel Alberto

2003 «Flechadores de jornales. Identidad guaraní en el Paraguay contemporáneo », Suplemento Antropológico, 38 (1), pp. 217-241 [http ://alhim. revues.org/index120.html, consulté le 10/06/2005].

BERTONI Moisés S.

1941 «Los guayakíes. Caracteres antropológicos, razas etnológicas y reseña cultural », Revista de la Sociedad Científica del Paraguay, 5 (2), pp. 1-62.

CAdogan León

1959 Ayvu Rapyta, textos míticos de los mbyá-guarani del Guairá, Universidad de São Paulo/Faculdad de Filosofia, coll. «Antropólogia » 227 (5), Sao Paulo.

1968a «Chono Kybwyra: aporte al conocimiento de la mitología guarani », Suplemento Antropológico, 3 (1-2), pp. 55-158.

1968b Diccionario Guayaki-Español, Musée de l'Homme, Paris 
1992 Diccionario Mbyá-Guaraní-Castellano, Biblioteca Paraguaya de Antropología, XVII, Asunción.

Cadogan León et Maxence de Colleville

1963 «Les Indiens guayaki de l'Yñarô (Paraguay)»(Première partie), Bulletin de la Faculté des Lettres de Strasbourg, 3 (8), mai-juin, pp. 41-60.

1964 «Les Indiens guayaki de l'Yñarô (Paraguay)» (Seconde partie), Bulletin de la Faculté des Lettres de Strasbourg, 4 (8), mai-juin, pp. 21-54.

Callegari Jacques Sidia M., Shaiane G. Grossetti, Fabiana B. Kohlrausch, Francisco M. Salzano, Luiza T. Tsuneto, Maria Luiza Petzl-Erler, Kim Hill et Ana Magdalena Mara H. Hutz

2007 "The beta-globin gene cluster distribution revisited-patterns in Native American populations ", American Journal of Physical Anthropology, 134 (2), pp. 190-197.

Clastres Pierre

1967 «Ethnologie des Indiens guayaki, la vie sociale de la tribu », L'Homme, 7 (4), pp. 5-24.

1968 «Ethnographie des Indiens guayaki (Paraguay-Brésil)», Journal de la Société des Américanistes, 57, pp. 9-61.

1972 Chronique des Indiens guayaki, Plon, coll. « Terre Humaine », Paris.

Clastres Pierre et Lucien Sebag

1964 «Cannibalisme et mort chez les Guayakí (Achén) 》, Revista do Museu Paulista, 14, pp. 174-181.

Dooley Robert A.

1998 Léxico Guaraní, Dialeto Mbyá : versão para fins acadêmicos (com acréscimos do dialeto nhandéva e outros subfalares do sul do Brasil), Sociedade Internacional de Lingüística, Porto Velho, RO, Brasil.

Dujovne Ortiz Alicia

2009 «El último viaje de Damiana », La Nación (Argentina), 28 de diciembre [http ://www.lanacion.com.ar/nota.asp?nota_id=1216044, consulté le 30/12/2009].

Edeb PIRagi Philippe

1991 «Chasse et symbolisme chez les Aché du Paraguay oriental », Annales de la Fondation Fyssen, 5-6, pp. 56-62.

1992 «Les Aché du Paraguay et le palmier pindo : éléments pour un réexamen de la stratégie économique et du mode de résidence ", Anthropologie et Sociétés, 16 (2), pp. 135-158.

1994 «El amansamiento de la naturaleza : del alimento al símbolo entre los aché, cazadores recolectores del Paraguay Oriental », Suplemento Antropológico, 29 (1-2), pp. 7-64.

1998 Sauvegarde et revitalisation du patrimoine oral des Indiens aché du Paraguay Oriental- «Jypywaregi Jawu»: la parole des ancêtres, Ambassade de France au Paraguay, Assomption [manuscrit].

2000 «Entre crime écologique et ethnocide: l'exode forcé de 300 Indiens achés, au Paraguay », La Lettre de la Fondation (France-Libertés), 13, pp. 9-10, Paris. 
2001 «Los Aché del Paraguay y las revelaciones de la Palabra de los Ancestros. De la tradición oral a la resistencia cultural », Suplemento Antropológico, 36 (1), pp. 147-243.

2005 «De la scierie à la réserve écologique: quel devenir pour les Aché, ex-nomades forestiers du Paraguay oriental? », Journal de la Société des Américanistes, 91 (1), pp. 211-226.

2008 "Y se hizo la luz" : proceso de transfiguración étnica y resiliencia entre los aché de Paraguay ", in IWGIA, Los Aché del Paraguay : discusión de un genocidio, Ennio Ayosa impresores, Buenos Aires, pp. 179-220.

\section{Edeb Piragi Philippe et Hilario Kanjegi}

s. d.a Diccionario Aché norteño (histórico-contemporáneo)-Español (2 tomos) [en préparation].

s. d.b Guía de ciencias naturales de los aché norteños (Paraguay oriental) [en préparation].

Edeb Piragi Philippe, Emiliano Mbejyvagi et Gloria ScapPini

2002 «Semblanza de un gran luchador indígena : el militante Aché Kuchîngi (Luis Duarte Vazquez) 1932(?)-2002 », La Nación, 367, pagina cultural, 25 de agosto [www.linaje.org (rubrique «In Memoriam»), consulté le 07/09/2002].

ERIKSON Philippe

1996 La Griffe des aïeux. Marquage du corps et démarquage ethnique chez les Matis d'Amazonie, Éditions Peeters, Paris.

1998 «Du pécari au manioc ou du riz sans porc ? Réflexions sur l'introduction de la riziculture et de l'élevage chez les Chacobo (Amazonie bolivienne) », Techniques \& Culture, 31-32, pp. 363-378.

\section{ESCOBAR Ticio}

1988 Misión: etnocidio, comisión de solidaridad con los pueblos indígenas, RP ediciones, Asunción.

Gurven Michael, Kim Hill et Hillard Kaplan

2002 «From forest to reservation : transitions in food-sharing behavior among the Aché of Paraguay», Journal of Anthropological Research, 58, pp. 93-120.

Hawkes Kristen, Hillard KaPlan, Kim Hill et Magdalena Hurtado

1987 "Ache at the settlement contrasts between farming and foraging ", Human Ecology, 15, pp. 133-161.

HERVÁs Y PANDURO Lorenzo

1800-1805 Catálogo de las lenguas de las naciones conocidas y numeración, división y clases de éstas, según la diversidad de sus idiomas y dialectos, 6 vol., Imprenta de la Administración del Real Arbitrio de Beneficencia, Madrid

HiLl Kim et Kristen Hawkes

1983 «Neotropical Hunting among the Ache of Eastern Paraguay », in Raymond Hames et William Vickers (éd.), Adaptive responses of Native Amazonians, Academic Press, New York, pp. 139-188. 
Hill Kim, Hillard Kaplan, Kristen Hawkes et Magdalena Hurtado

1984 "Seasonal variance in the diet of Ache hunter-gatherers of Eastern Paraguay », Human Ecology, 12, pp. 145-180.

Hill Kim et Magdalena Hurtado

1996 Ache life history : the ecology and demography of a foraging people, Aldine de Gruyter, New York.

1999 "The Ache of Paraguay », in Richard Lee et Richard Daly (éd.), The Cambridge encyclopedia of hunters and gatherers, Cambridge University Press, Cambridge, pp. 92-96.

IWGIA

2008 Los aché del Paraguay : discusión de un genocidio, Ennio Ayosa impresores, Buenos Aires.

LINAJE (Liga Nativa por la Autonomía, Justicia y Ética)

2006 «Pronunciamiento sobre el convenio SEAM/INDI/KUÊTUVY del 02/09/2004 y el decreto 6673 del 5/12/2005», 06/02/2006 [www.linaje.org (sección : noticiero), consulté le 10/09/2004].

2007 «Siguen el ecocidio y etnocidio en contra del pueblo aché », 20/03/2007 [www.linaje.org (sección : noticiero), consulté le 22/03/2007].

2007 "Llamado al estado paraguayo y al pueblo aché », 07/05/2007 [www.linaje.org (sección : noticiero), consulté le 12/05/2007].

2010 «Tras 114 años, el museo de La Plata restituye restos humanos al pueblo aché », 11-12/06/2010 [www.linaje.org (sección : noticiero), consulté le 14 juin 2010].

MAYNZhusen Friedrich C.

1911 «Los indios matacos del Sudeste del Paraguay. Su influencia sobre los guayakí », Revista de la Universidad de Buenos Aires, 15-16, pp. 333-344.

1912 «Über die Gebräuche bei der Geburt und der Namengebung der Guayaki », Proceedings of the XVIII, International Congress of Americanists, Harrison and sons, Londres, pp. 408-412.

1919-1920 «Die Sprache der Guayakí», Zeitschrift für Eingeborenensprachen, 10, pp. 2-22, Berlin.

1925 «Guayakí-Forschungen », Zeitschrift für Ethnologie, 57, pp. 315-318.

2009 Los aché guayakí, Junta de Estudios Históricos de Misiones, Posadas, Argentina.

MeLià Bartomeu

2008 «Pueblos indígenas en Paraguay y violación de los Derechos Humanos (1958-2003) », in IWGIA, Los aché del Paraguay : discusión de un genocidio, Ennio Ayosa impresores, Buenos Aires, pp. 135-146.

Melià Bartomeu, Luigi Miraglia, Mark Münzel et Christine Münzel

1973 La agonía de los aché-guayakí: historias y cantos, Centro de Estudios Antropológicos, Universidad Católica « Nuestra Señora de la Asunción », Asunción.

Ministerio Público del Paraguay

1999 Los guaraní del Paraguay oriental, Informe antropológico-jurídico, Asunción. 
MÜNZEL Mark

1973 The Aché Indians: genocide in Paraguay, IWGIA, Document 11, Copenhague.

1974 The Aché Indians : genocide continues in Paraguay, IWGIA, Document 17, Copenhague.

2008 «Prólogo : 35 años después », in IWGIA, Los aché del Paraguay : discusión de un genocidio, Ennio Ayosa impresores, Buenos Aires, pp. 7-23.

RENFELD Marilín

2000 «Etnohistoria de las Caaguá (Guaraní) del este paraguayo (1537-1669) », Suplemento Antropológico, 35 (1), pp. 91-181, Asunción.

RENSHAW John et Richard REED

1990 «Las comunidades aché y chiripá-guaraní de Canindeyú », Suplemento Antropológico, 25 (2), pp. 19-51, Asunción.

SERvín Jorge Aníbal

2008 «Stroessner, su dictadura y los impactos en el pueblo aché », in IWGIA, Los aché del Paraguay : discusión de un genocidio, Ennio Ayosa impresores, Buenos Aires, pp. 147-177.

SMITH Robert J.

1975 «La vida en la muerte de los aché-guayakí », Suplemento Antropológico, 10 (1-2), pp. 135-176, Asunción.

Smith Robert J. et Bartomeu Melià

1978 «Genocide of the Aché-Guayakí ? », Survival International, 3 (1), pp. 8-13, Londres.

STRELNIKov Ivan D.

1928 "Les Kaa-îhwuas du Paraguay », Atti del XXII Congresso Internazionale degli Americanisti (Roma, 1926), II, pp. 333-366.

SusNiK Branislava et Miguel CHASE-SARDI

1995 Los indios del Paraguay, Editorial MAPFRE S. A.,.

Tsuneto Luiza T., C. M. Probst, Mara H. Hutz, Federico M. Salzano,

L. A. Rodriguez-Delfin, M. A. Zago, Kim Hill, Ana Magdalena Hurtado,

A. K. C. Ribeiro-Dos-Santos et Maria Luiza Petzl-Erler

2003 "HLA class II diversity in seven Amerindian populations. Clues about the origins of the Aché tribe », Tissue Antigens, 62, pp. 512-526.

VeLlard Jean

1935 «Les Indiens Guayakis », Journal de la Société des Américanistes, 27 (1), pp. 175-244. 